\title{
Meta-analysis of Nekton Utilization of Coastal Habitats in the Northern Gulf of Mexico
}

\author{
Terill A. Hollweg ${ }^{1}$ (1) $\cdot$ Mary C. Christman ${ }^{2} \cdot$ Just Cebrian $^{3,4,5} \cdot$ Bryan P. Wallace $^{6,7} \cdot$ Scott L. Friedman ${ }^{8}$. \\ Heather R. Ballestero ${ }^{8} \cdot$ Mary T. Huisenga ${ }^{1,9} \cdot$ Kristopher G. Benson $^{10}$
}

Received: 20 October 2018 / Revised: 3 September 2019 / Accepted: 11 September 2019 / Published online: 29 October 2019

(C) The Author(s) 2019

\begin{abstract}
Estuaries in the northern Gulf of Mexico (GOM) provide habitat for many ecologically, commercially, and recreationally important fish and crustacean species (i.e., nekton), but patterns of nekton abundance and community assemblages across habitat types, salinity zones, and seasons have not been described region-wide. Recognizing the wealth of information collected from previous and ongoing field sampling efforts, we developed a meta-analytical approach to aggregate nekton density data from separate studies (using different gear types) that can be used to answer key research questions. We then applied this metaanalytical approach to separate nekton datasets from studies conducted in the Gulf of Mexico to summarize patterns in nekton density across and within several estuarine habitat types, including marsh, oyster reefs, submerged aquatic vegetation (SAV), and open-water non-vegetated bottom (NVB). The results of the meta-analysis highlighted several important patterns of nekton use associated with these habitat types. Nekton densities were higher in structured estuarine habitats (i.e., marsh, oyster reefs, SAV) than in open-water NVB habitat. Marsh and SAV community assemblages were relatively similar to each other, but different from those associated with open-water NVB and oyster habitats. Densities of commercially and recreationally important crustacean and fish species were highest in saline marshes, thus demonstrating the importance of this habitat in the northern GOM. The results of our meta-analysis are generally consistent with previous site-specific studies in the region (many of which were included in the meta-analysis) and provide further evidence for these patterns at a regional scale. This meta-analytical approach is easy to implement for diverse research and management purposes, and provides the opportunity to advance understanding of the value and role of coastal habitats to nekton communities.
\end{abstract}

Keywords Nekton $\cdot$ Community assemblage $\cdot$ Marsh $\cdot$ Oyster reefs $\cdot$ SAV $\cdot$ Gulf of Mexico

Communicated by Henrique Cabral

Electronic supplementary material The online version of this article (https://doi.org/10.1007/s12237-019-00633-y) contains supplementary material, which is available to authorized users.

Terill A. Hollweg

terill_hollweg@abtassoc.com

1 Abt Associates, 1881 Ninth Street, Suite 201, Boulder, CO 80302, USA

2 MCC Statistical Consulting LLC, 2219 NW 23rd Terrace, Gainesville, FL 32605, USA

3 Department of Marine Sciences, University of South Alabama, Mobile, AL 36688, USA

4 Dauphin Island Sea Laboratory, Marine Environmental Sciences Consortium, Dauphin Island, AL 36528, USA
5 Northern Gulf Institute, Mississippi State University, 1021 Balch Blvd, Stennis Space Center, MS 39529, USA

6 Conservation Science Partners, Inc., 5 Old Town Square, Suite 205, Fort Collins, CO 80524, USA

7 Nicholas School of the Environment, Duke University Marine Laboratory, 135 DUML Road, Beaufort, NC 28516, USA

8 Industrial Economics, 2067 Massachusetts Avenue, Cambridge, MA 02140, USA

9 Present address: SWCA, 295 Interlocken Boulevard, Suite 300, Broomfield, CO 80021, USA

10 NOAA Restoration Center, 4700 Avenue U, Bldg. 307, Galveston, TX 77551, USA 


\section{Introduction}

Estuarine habitats in the northern Gulf of Mexico (GOM) are important for many ecologically and economically important fish and crustacean species (hereafter referred to collectively as "nekton"; Boesch and Turner 1984; McIvor and Rozas 1996; Deegan et al. 2000; Zimmerman et al. 2000; Beck et al. 2001; Minello et al. 2003), and facilitate vital ecological connectivity (e.g., exchanging nutrients and energy) between estuarine and marine environments (Deegan 1993; Deegan et al. 2000). Within these estuarine systems, structured habitats, including marsh, oyster reefs, and submerged aquatic vegetation (SAV), support higher densities of nekton species than non-vegetated bottom (NVB) habitats (e.g., Rozas and Minello 1998; Castellanos and Rozas 2001; Shervette and Gelwick 2008; Stunz et al. 2010; Shervette et al. 2011). This pattern remains consistent for many resident species (e.g., grass shrimp, killifish) that serve as prey resources for larger organisms, as well as for many transient species that use these habitats temporarily for breeding, juvenile development, or foraging (Zimmerman and Minello 1984; Minello and Zimmerman 1991; Baltz et al. 1993; McIvor and Rozas 1996; Beck et al. 2001) before moving offshore as adults (Able and Fahay 1998; Able 2005). Many of these transient species-e.g., brown shrimp (Farfantepenaeus aztecus), white shrimp (Litopenaeus setiferus), blue crab (Callinectes sapidus), Gulf menhaden (Brevoortia patronus), spotted sea trout (Cynoscion nebulosus), and red drum (Sciaenops ocellatus) - are also commercially and recreationally important (O'Connell et al. 2005). For example, over $95 \%$ of the US commercial fisheries landings (by weight) in the GOM are estimated to be comprised of estuarine-dependent species (Chambers 1992; Lellis-Dibble et al. 2008), and the GOM accounted for approximately $14 \%$ of the total US domestic commercial fisheries landings (by weight) and $16 \%$ of the total dollar value in 2017 (NMFS 2018).

Given the importance of estuarine habitats in the northern GOM, a strong understanding is needed of nekton abundance patterns among, and assemblage structure within, these habitat types. The Magnuson-Stevens Fishery Conservation and Management Act (Magnuson-Stevens Act), the primary law governing marine fisheries management in US federal waters, requires that essential fish habitat be identified and conserved. According to the Magnuson-Stevens Act, essential fish habitat includes "those waters and substrate necessary to fish for spawning, breeding, feeding, or growth to maturity" (50 CFR $\S 600.10)$. In this context, the ability to describe the spatial and temporal use of such habitats by nekton is essential to ensure the conservation, restoration, and management of habitats that are critical to maintaining healthy nekton populations for both ecological and commercial purposes.

Although significant field sampling efforts to describe species- and habitat-specific nekton densities have been made in the past decade, only a few studies have attempted to summarize patterns of nekton densities at regional or global scales (e.g., Minello 1999; Minello et al. 2003). Reasons for this may be several fold, including the time required to compile data from separate studies, the need to standardize data across studies (and gear types), and the analytical methods required to summarize results. Regardless of these limitations, a metaanalysis, which is a statistical method for combining results from two or more separate studies (Higgins and Green 2011), provides the opportunity to summarize research findings across comparable studies (Vetter et al. 2013). Contrary to site-specific studies, this method also allows for interpreting effects as general principles valid over many locations or time periods.

Recognizing the wealth of information collected by previous and ongoing field sampling efforts, the objective of this study was to leverage this existing work and develop a metaanalytical approach to summarize patterns in nekton density across and within estuarine habitat types in the GOM. This approach allows for the summarization of nekton density results from separate studies and includes the (1) application of gear correction factors to density estimates, (2) imputation of standard error (SE) values for densities missing SEs, and (3) application of a random effects model to calculate weighted average densities for different treatments. Using nekton density data reported in the scientific literature, we then applied this novel meta-analytical approach to evaluate common spatial and seasonal patterns in nekton density across and within four estuarine habitat types, including marsh, oyster reefs, SAV, and open-water NVB. This meta-analytical approach is easy to implement for diverse research and management purposes, and provides the opportunity to advance understanding of the value and role of coastal habitats to nekton communities.

\section{Methods}

\section{Nekton Density Data Compilation}

We compiled information related to nekton density and abundance reported in the scientific and grey (e.g., theses, dissertations, reports) literature to evaluate nekton utilization of coastal habitats in the northern GOM. In particular, we conducted an extensive literature search consisting of a keyword search, an author-based search, and supplemental searches ("Literature Search" section). We reviewed papers for relevant data on nekton densities in coastal habitats of the northern GOM ("Publication Screening" section), extracted and compiled relevant data, and performed a $100 \%$ quality control (QC) check to verify correct data entry ("Data Extraction, Compilation, and QC Methods" section). The following sections describe in more detail the methods used. 


\section{Literature Search}

We used ProQuest (http://www.proquest.com/) to conduct a keyword search in 12 databases (Table S1 in Supplement 1) using a standardized set of relevant search terms (Table S2 in Supplement 1). We then conducted an author-based search in the same 12 databases with no additional limiters on authors with 4 or more publications identified in the initial search; we also included 3 additional authors who appeared 3 times in the keyword search and who wrote papers we previously found relevant (Table S3 in Supplement 1). The keyword and authorbased searches were completed on April 24 and May 29, 2014 , respectively. The literature searches were performed for any publications up until the date of the search (i.e., April 24 and May 29, 2014, respectively). Furthermore, to ensure we identified a comprehensive list of relevant publications, we also conducted similar searches using online search engines (e.g., Google Scholar, Louisiana State University Electronic Thesis and Dissertation Library) and reviewed publications already familiar to the research team from previous related work (including publications that had been cataloged in the in-house library of the principal investigators).

\section{Publication Screening}

To determine whether identified publications contained relevant information on nekton utilization of coastal habitats in the northern GOM, we developed an initial screening protocol consisting of five criteria: (1) studies that occurred along the US coast of the GOM, extending from Laguna Madre in southern Texas to the Caloosahatchee River in southern Florida; (2) studies that were located in one or more of the following habitats: marsh, mangroves, oyster reefs, SAV, or open-water NVB; (3) studies that were located in a natural or restored habitat (i.e., not substantially impacted or degraded, as characterized by the author); (4) studies that contained field-collected nekton data (i.e., not laboratory-based studies); and (5) studies that reported density, abundance, biomass, length, or catch-per-unit-effort (CPUE) for all nekton, all fish, all crustaceans, or by species for at least three nekton species. If all five criteria were met, we retained the documents for additional review and data extraction. Papers that did not meet all five criteria were excluded from further review. The excluded papers included, but were not limited to, studies located outside of the area of interest, studies conducted in an impacted or degraded habitat, studies reporting only presence/absence data, and studies only reporting data for one or two species of interest.

\section{Data Extraction, Compilation, and QC Methods}

We extracted data on nekton density, abundance, biomass, length, and CPUE and compiled them in an electronic database. Data tables were extracted from the published literature using Able2Extract Professional 8 software (http://www. investintech.com/), and data presented in the figures were manually extracted using DataThief III software (Tummers 2006). All extracted data were checked against the original tables or figures to ensure that no transcription errors occurred during the extraction process. When available, we also recorded sample size (N), SE, and standard deviation (SD). If the document did not explicitly report the sample size, we reviewed the methods section to calculate a sample size or we contacted the primary author for clarification. If we could not ascertain this information, we left these fields blank.

To ensure that our methods were consistent and transparent during the compilation process, we developed a set of processing guidelines. First, we compiled individual species data and group totals (e.g., total nekton density, total fish density, total crustacean density) as reported in the original document. Sometimes the author(s) reported zero density or abundance values. This could result, for instance, from a species being present in one season but not in the other, or from a very low value rounded up to zero. We retained such zero values in our database. However, we did not populate a zero density or abundance value for species not reported by the author(s). This could be, for instance, because the species was not caught at all during the study, or because the study only reported the most abundant species.

To compare data across studies we conducted basic calculations where appropriate, including (1) standardizing density to units of number per $\mathrm{m}^{2}$ (such as converting a density reported in units of number per $2.6 \mathrm{~m}^{2}$ to units of number per $\mathrm{m}^{2}$ ); (2) calculating density if abundance and sampling area were reported but density was not calculated by the author(s); and (3) computing a total value for a group of species if the publication author(s) had not calculated this value and provided information that allowed this calculation (e.g., reported mean densities of all species collected, or reported total crustacean density and total fish density). When mean densities of all species were reported, we summed the values to obtain the mean total nekton density, referred to as $\bar{y}_{T O T A L}$. When only total crustacean density $\left(\bar{y}_{C}\right)$ and total fish density $\left(\bar{y}_{F}\right)$ were reported, we calculated a total nekton density $\left(\bar{y}_{\text {TOTAL }}\right)$ by summing

$\bar{y}_{\text {TOTAL }}=\bar{y}_{C}+\bar{y}_{F}$

The SE for total nekton density was calculated as $S E$ $\left(\bar{y}_{\text {TOTAL }}\right)=\sqrt{\sum_{\text {all taxa }} S E_{\text {taxon }}^{2}}$ assuming that the reported densities were independent. If the SEs for the two groups of organisms were provided, we calculated the SE of the combined total using:

$S E\left(\bar{y}_{T O T A L}\right)=\sqrt{S E_{C}^{2}+S E_{F}^{2}}$

We were comfortable assuming independence because the Spearman's rank correlation between the two densities was 
negligible $(r=0.06, N=246)$ using records that contained both total crustacean density and total fish density.

We also included metadata for each study. We assigned habitat type based on the habitat (i.e., marsh, mangroves, oyster reefs, $\mathrm{SAV}$, or open-water NVB) reported by the author. We assigned vegetation type (i.e., saline, brackish, intermediate, fresh) based on the vegetation community at the site as reported by the author(s), following the classification scheme outlined in Visser et al. (1998, 2000, 2002), Sasser et al. (2014), and Enwright et al. (2014). If the vegetation community was not reported, we cross-referenced the project location with available vegetation maps, including the vegetation layers displayed in the Coastwide Reference Monitoring System online viewer (http://lacoast.gov/crms2/home.aspx) and state-specific maps for Louisiana (Sasser et al. 2014) and Texas (Enwright et al. 2014). We used the marsh vegetation type as a proxy for salinity because it represents average environmental conditions over time rather than a single salinity measurement at a location, which may vary greatly over different temporal scales (Rozas and Minello 2010; Mace III and Rozas 2017). The typical range in salinity is from 8 to $29 \mathrm{ppt}$ (average $18 \mathrm{ppt}$ ) for saline marsh, 4 to $18 \mathrm{ppt}$ (average $10 \mathrm{ppt}$ ) for brackish marsh, 2 to $8 \mathrm{ppt}$ (average $4 \mathrm{ppt}$ ) for intermediate marsh, and 0 to $3 \mathrm{ppt}$ (average $0 \mathrm{ppt}$ ) for fresh marsh (Chabreck 1970; Visser et al. 1998). For sampling sites located in oyster, SAV, or open-water NVB habitats, we recorded the vegetation type based on the adjacent marsh characteristics.

We further classified marsh and open-water habitats based on distance to the marsh shoreline, if this information was reported by the author(s). We classified marsh habitat as "edge" or "interior." A sampling site was classified as marsh edge if the site was located on the vegetated surface $<5 \mathrm{~m}$ from the marsh shoreline (i.e., the interface between open water and emergent vegetation), and as marsh interior if the sampling site was on the vegetated surface and located $\geq 5 \mathrm{~m}$ inland from the marsh shoreline. Furthermore, we classified open-water NVB habitats as "near" if the sampling site was located in the open water $<5 \mathrm{~m}$ from the marsh shoreline, or "far" if the sampling site was located in the open water $\geq 5 \mathrm{~m}$ from the marsh shoreline. We did this to account for marsh fringing edge effects when comparing nekton abundance between the marsh and adjacent open water. Previous work (e.g., Minello and Rozas 2002; Minello et al. 2008) has shown that nekton tend to concentrate around the marsh edge and its abundance decreases farther into the marsh or off the marsh into adjacent open water. We chose $5 \mathrm{~m}$ as an adequate distance to capture such gradients as shown in these previous studies.

Additionally, for the purposes of this analysis, we recorded season based on timing of the sampling: March, April, and May (spring); June, July, and August (summer); September, October, and November (fall); and December, January, and
February (winter). In many cases, sampling sites within a study were conducted across multiple habitat types, vegetation types, landscape positions (e.g., edge, interior), and seasons. In these cases, we compiled the non-aggregated data if possible and reported the specific site information associated with each datapoint. Finally, we conducted a $100 \%$ independent QC check of the compiled database to ensure no errors were introduced during the data extraction and compilation process.

\section{Gear Correction Factors}

Sampling gear types vary in their ability to capture target organisms, and their capture ability may differ across different habitats (Rozas and Minello 1997). As such, we developed habitat-specific gear correction factors for the different gear types included in the database, including enclosure gears (e.g., block net, drop net, throw trap, drop sampler, lift net, cast net); towed gears (e.g., otter trawl, beam trawl, hand trawl, seine, push trawl, epibenthic sled); and passive gear (e.g., substrate tray). We then applied these gear correction factors to the reported density values based on the specific habitat type and gear that was used. The same correction factor was applied to all species or group of species within the same gearhabitat combination.

For purposes of this study, we considered the ability of a gear to capture nekton by three metrics: gear selectivity, capture efficiency, and recovery efficiency. First, gear selectivity is constrained by the maximum and minimum individual nekton size that the gear normally captures. Given the way they operate, some gears will capture few to no individuals smaller or larger than a certain size. For instance, most enclosure gears normally sample a relative small area and typically miss relatively larger individuals $(>100 \mathrm{~mm}$ ) present in the population (Rozas and Minello 1997, 1998; Minello and Rozas 2002; Baker and Minello 2011). Thus, gear selectivity corresponds to the fraction of individuals in the population with a size apt for capture with the gear, which is defined by the minimum or maximum size threshold the specific gear can capture. The second metric, over-imposed on gear selectivity, is gear capture efficiency, which is defined as the fraction of size-apt individuals within the sample unit area that are actually enclosed or captured by the gear (Rozas and Minello 1997). Finally, the last metric is gear recovery efficiency, which is over-imposed on gear capture efficiency. It corresponds to the fraction of individuals enclosed by or taken into the gear that are actually recovered from the sampling device and processed (Rozas and Minello 1997). This final correction factor is mostly applicable to gears with a secondary removal method (e.g., drop samplers cleared of nekton using a small mesh net after deployment). For gear types without a secondary removal method, we assumed that recovery efficiency is $100 \%$. However, there may be instances where this is not the case, such as if individuals are not found due to debris in 
the sampler device (e.g., detritus, grass) or smaller sized individuals.

Because corrections for gear capture and recovery need to be applied to the compiled nekton density data, we conducted a literature search of gear capture and recovery efficiency values (Supplement 2). The search for gear efficiency values was guided by the recommended gear-habitat combinations in Rozas and Minello (1997) and the gear-habitat combinations in the data compilation ("Nekton Density Data Compilation" section). We searched correction values for all the combinations of gear type and habitat type in the database. We screened references, and extracted and compiled efficiency values and SEs for each study. For the several papers that provided mean efficiency values but not SEs, we used an imputation method similar to the one used to estimate the SE for nekton density entries (see "SE Imputation" section). Both capture and recovery efficiency values were used in the regression between SD and mean values.

We found that the compiled mean efficiency values normally corresponded to different species or locations across studies. We ran a weighted fixed effects meta-analytical model with efficiency as the response and habitat, efficiency type (capture or recovery), and gear as fixed effects or moderators. The results were almost identical to the simpler unweighted means estimation approach, likely due to the small sample sizes within each combination of habitat, efficiency type, and gear type. Due to this, we chose to use the unweighted means when calculating the overall mean across studies for each habitat, gear type, and efficiency type combination. Assuming independence among records, the SE for the unweighted grand mean was calculated as

$S E_{\text {across }- \text { study mean }}=\sqrt{\frac{1}{n^{2}}\left(S E_{\text {study } 1}^{2}+S E_{\text {study } 2}^{2}+\ldots+S E_{\text {study } n}^{2}\right)}$

where $n$ is the total number of records used in calculating each overall mean. Finally, despite the extensive literature search, we found no capture and recovery efficiency values for some gear-habitat combinations in the database. To resolve this, we followed a hierarchical approach and assigned surrogate estimates to such combinations using the values compiled for other combinations directly reported in the literature (see Supplement 2). The surrogate assignment was done separately for capture and recovery values. The final capture and recovery efficiency values for each gear-habitat combination are shown in Tables S2 and S3 in Supplement 2. While these corrections were developed based on the best available information, we acknowledge that gear efficiencies may vary by habitat characteristics (e.g., vegetation structure), environmental conditions (e.g., water clarity, water depth), and sampling team.

Gear selectivity corrections can be attempted, as needed, when individuals for the species of interest are outside the minimum or maximum size thresholds for the gear types used.
To carry out such corrections, we need to know the minimum and maximum size thresholds that can be captured with the specific gear, and the individual size distribution of the fish populations targeted before sampling. Accurate size thresholds are known for only a few gears. In addition, one can infer individual size distributions at the time of sampling based on previous studies, but certainly around such distributions cannot be estimated without uncertainty. Based on this, we made no efforts to correct for gear selectivity. Regarding minimum size thresholds, most of the gear types included here have a mesh size equal to or smaller than $5 \mathrm{~mm}$ and thus would miss recently arrived juveniles (i.e., within 1 or 2 months from arrival in estuarine habitats) for transient species, and the post-larval and early juvenile stages for resident species. Regarding maximum size thresholds, enclosure-type gears (e.g., drop sampler, throw trap, drop net) have a lower threshold than towed- and passive-type gears, and thus would miss a significant number of larger individuals in the populations targeted. The lack of correction for gear selectivity must be regarded as a caveat and considered adequately when interpreting our results.

\section{Density Estimation}

We estimated densities and associated SEs for a variety of species, habitats, and seasons using a meta-analytic approach. First, where reported densities were missing SEs, we used a regression approach to impute these values ("SE Imputation" section). Second, we corrected each reported density for gear efficiency for the relevant species, habitat, and season in order to standardize densities to a common metric ("Correcting Density for Gear Efficiency" section). Finally, we performed a meta-analysis using a random effects model to provide weighted average densities for each species, habitat, and season of interest ("Meta-analysis to Estimate Mean Density by Species, Habitat, and Season of Interest" section).

\section{SE Imputation}

In order to perform a meta-analysis of density and its relationship to habitat or season, observations require both a density and its associated SE. The SEs are needed in order to perform the meta-analysis using weights that are inversely proportional to the SE of an observation as a mechanism for incorporating uncertainty about the estimated density into the model. Since records without a SE would have to be excluded from analyses, we used an expected relationship between the sample mean and sample SD to impute missing SEs. Relationships between means and SDs are common with count data (Hilbe 2014); for example, count data often have probability distributions, such as the Poisson or Negative Binomial distributions where the variance is a function of the mean. In the case of the data compiled for our paper, we found a linear 
relationship between the reported densities and the associated SDs. Therefore, we used predicted values from a fitted regression to impute the missing SDs, which were then in turn used to calculate missing SEs.

The first step was to convert all reported SEs greater than zero to SDs assuming that the reported mean density was obtained from a simple random sample. That is, we calculated $S D_{i}=S E_{i} \sqrt{n_{i}}$ where the subscript $i$ indexes the $i^{t h}$ record and $n_{i}$ is the reported sample size used to estimate the mean density for the $i^{t h}$ record. Density values reported as zero, with an associated SD higher than zero (i.e., very low density values rounded down to a value of zero), were included in the regression. The SD values were then regressed on the reported densities by species to obtain estimated linear fits between mean density and SD for each species. Appropriate diagnostics were conducted (e.g., reviewing the residuals for outliers, linearity in the relationship, influential observations) to ensure that the estimated linear regression between the mean and SD was appropriate (Quinn and Keough 2002).

The least squares estimates of the relationships were then used to impute SDs for those records with mean densities but missing SE values (approximately 30\% of the dataset). For those records with reported SEs $>0$, no changes were made. For those records with a missing SE, if a sample size $n_{i}$ was reported, we calculated the $\mathrm{SE}$ using $S E_{i}=S D_{i} / \sqrt{n_{i}}$ where the SD was either reported or imputed. If the sample size was not reported, we set $n_{i}=1$ which has the effect of assuming a high level of uncertainty since this sets the SE of the mean to the SD of the sample. This ensures that records with the least information about uncertainty in their estimates (i.e., no sample size reported) would have the highest estimates of uncertainty associated with them (and hence the smallest weights), and effectively decreased their contribution to the calculation of the overall mean in the meta-analysis. Yet, this approach also inflated the derived estimate for the SE of the overall mean (see "Meta-analysis to Estimate Mean Density by Species, Habitat, and Season of Interest" section).

The regressions were also used to estimate SD for density values reported as zero with no SE or with a reported SE value of zero. Such estimations are approximations of the variability of very low true density values. Furthermore, for a few taxa (6 out of 54; i.e., sheepshead (Archosargus probatocephalus), hardhead catfish (Ariopsis felis), thinstripe hermit (Clibanarius vittatus), brackish grass shrimp (Palaemonetes intermedius), daggerblade grass shrimp (Palaemonetes), and total nekton), the regression relationship estimated a negative SD for estimates of density near or equal to zero (i.e., the intercept coefficient was less than zero). In these instances, the intercept was not statistically significantly different from 0 . However, we could not impute a SD of zero since that would cause the meta-analysis to remove any records with a zero SE. Hence, we reran the regression models for these taxa restricting the intercept to the upper bound of the $90 \%$ confidence interval for the intercept. This procedure provided models with predicted values for SD virtually identical to those with the unrestricted intercept except that all values were strictly positive. The overall effect on the subsequent metaanalysis was to slightly down-weight those records with SDs near zero for these six taxa. The alternative would have been to remove these records completely from all analyses. For hardhead catfish ( $A$. felis) and sheepshead (A. probatocephalus), over $70 \%$ of all records $(n=68$ and 58 , respectively) would have been excluded from the analyses. Between 30 and $50 \%$ of the records would have been excluded for the other three species, and $\sim 6 \%$ would have been excluded for total nekton. Thus, our approach generates SE estimates for very low density levels that should be reflective of the true SEs associated with the true density values of the populations, if we had been able to measure it with accuracy. Also, critically, our approach allows for the inclusion of very low density values (and rounded zero values) for a more accurate derivation of our weighted average calculations (see "Meta-analysis to Estimate Mean Density by Species, Habitat, and Season of Interest" section).

A similar imputation method was used for the gear capture and recovery efficiency estimates when records had missing SEs (see "Gear Correction Factors" section). The difference here is that the expected relationship between the SD and the estimated mean gear efficiency (capture or recovery) was quadratic, as might be expected for proportions (Casella and Berger 2002). We imputed SEs using the least squares estimates from the quadratic regression predicting the missing SD of the gear efficiencies. Similar to the density imputations, we set missing sample sizes to 1 .

\section{Correcting Density for Gear Efficiency}

We calculated the overall gear efficiency $\left(G_{h g}\right)$ for each gearhabitat combination as a function of the capture and recovery efficiency:

$G_{h g}=C_{h g} R_{h g}$

where $C_{h g}\left(R_{h g}\right)$ is the capture (recovery) rate for the $h^{\text {th }}$ habitat and $g^{\text {th }}$ gear type (see "Gear Correction Factors" section for our methods to calculate capture and recovery efficiencies). The SE of the product was calculated using Goodman's (1960) equation for estimating the variance of the product of two independent random variables:

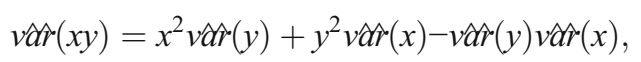

where $x(y)$ is an estimate of the mean of the random variable $X(Y)$, and $v \hat{a r}(a)$ is an estimate of the variance of $a$. 
The densities were corrected for gear efficiency using

$D_{i}^{C}=\frac{D_{i}}{G_{h g}}$,

where $D_{i}^{C}$ is the corrected density for the $i^{t h}$ record, $D_{i}$ is the reported density for the $i^{\text {th }}$ record, and $G_{h g}$ is the estimated gear efficiency (Eq. 5) for habitat $h$ and gear type $g$ associated with the $i^{\text {th }}$ record. The SE of the corrected density was obtained by first calculating the estimated variance of the inverse of the efficiency using the Delta method (Casella and Berger 2002) and then applying Goodman's (1960) equation (Eq. 6) for estimating the variance of the product of two independent random variables.

\section{Meta-analysis to Estimate Mean Density by Species, Habitat, and Season of Interest}

We used a meta-analytic approach to estimate the mean density and SE for each taxon within a given habitat (i.e., combinations of habitat type and vegetation type) and season. Data analyses were focused on comparing (1) nekton densities in marsh, oyster reef, SAV, and open-water NVB habitats in the saline zone during spring and fall; (2) nekton densities across the transition zone between marsh and open-water NVB (i.e., marsh edge, marsh interior, open-water far, open-water near) in the saline zone during spring and fall; and (3) nekton densities in saline, brackish, and intermediate marsh during spring and fall (Table S4 in Supplement 1). As a result of the filtering, we did not include density data that were combined across seasons, habitat types, or vegetation types or data that did not fit into the habitat-season combinations of interest. While this resulted in the exclusion of data from some studies included in our database, this focused meta-analysis allowed for the investigation of seasonal and habitat differences in species utilization of coastal habitats. Since many nektonic species in the Gulf of Mexico are transient and only use coastal habitats during a few specific months during the year, this metaanalysis captures these temporal trends in species utilization.

We limited our analyses to densities of total nekton (i.e., the sum of all fish and crustacean species), total fish (i.e., the sum of all fish species), total crustaceans (i.e., the sum of all crustacean species), and individual densities of 50 fish and crustacean taxa (Table S5 in Supplement 1). Of the close to 300 species in the database, we selected these 50 taxa due to their high densities, high sample numbers, and/or commercial/recreational importance. We included data from both reference and restored sites in the northern GOM in our analysis. We acknowledge that species densities and composition may vary between restored and reference sites for a given habitat; many studies have documented differences between restored and natural marsh habitats in the GOM (e.g., Minello and Zimmerman 1992; Minello and Webb 1997; Rozas and
Minello 2001; Zeug et al. 2007; Hollweg et al. 2019). This artifact of combining data from these two sources likely increases the variance in our estimates and may bias the results depending on the specific taxa. However, with the majority of studies being from reference sites for marsh, SAV, and openwater habitats, we believe this artifact had a relatively small effect on our results given all the other sources of error (e.g., differences in timing of sampling, gear, habitat characteristics, location). In addition to comparing absolute densities, we also calculated relative densities for the four habitat types in the saline zone during spring and fall to examine community composition. Relative densities were computed for crustacean and fish families in each habitat type by calculating proportional densities of each crustacean and fish family relative to the summed total density for that group of species (i.e., crustacean or fish) for each habitat type.

For each combination of habitat and season, we used a weighted random effects model where the random effect of study is included to allow for the likelihood that the records were not replicate observations from the same population (Aitkin 1999). This is a very likely scenario for these data as the specific sub-types of habitat combinations and geographic regions varied considerably. Our meta-analysis modeling used the SEs of the corrected densities and the random effect variance estimate $\tau^{2}$ to obtain weights for each record (entry), which were then used to calculate a weighted average of the records within each taxonomic group, habitat, and season:

weighted mean $=\frac{\sum \mathrm{w}_{\mathrm{i}}{ }^{*} \text { single entry mean }}{\sum \mathrm{w}_{\mathrm{i}}}$,

where $w_{\mathrm{i}}$ is calculated as $1 /\left(\mathrm{SE}_{\mathrm{i}}^{2}+\tau^{2}\right)$ and $\mathrm{SE}_{\mathrm{i}}$ is the $\mathrm{SE}$ for the given entry (each gear-corrected density value for the specific combination of taxon, habitat, and season). The measure of variability among studies $\left(\tau^{2}\right)$ captures variability in the reported outcomes that could be due to different field sampling approaches among the authors, differences in geographical study locations, differences in the environment surrounding the reported habitat, or subtle differences within season or habitats. However, in a few instances, it might be that the dataset is not sufficiently large (i.e., not enough records are available for specific data combinations in the analysis) to estimate $\tau^{2}$ accurately. In those instances, $w_{\mathrm{i}}$ would be calculated as $1 / \mathrm{SE}_{\mathrm{i}}^{2}$. We also calculated SEs of the model-based weighted means:

$\mathrm{SE}($ weighted mean $)=\sqrt{\frac{1}{\sum \mathrm{w}_{\mathrm{i}}}}$.

The entries weighted into the overall mean come from different studies.

In the calculation of the weighted mean for a particular taxon, we included density values that were reported as zero by the author(s) but did not assume that if the taxon was not 
reported by the author(s) it must therefore have a zero density (discussed in "Data Extraction, Compilation, and QC Methods" section above). We chose this approach since several of the studies used in this meta-analysis only reported the most abundant species collected and/or clearly specified the types of taxa targeted. Thus, we did not find it accurate to presume that every study that failed to report a species was an indication that the species was not observed. However, this approach may lead to overestimates when calculating the weighted mean densities values for particular species. Nevertheless, the calculated weighted mean density values generally come from multiple means covering many sites and zero density values were included if reported by the author(s). Thus, we believe that the possible degree of overestimation of some of our calculated weighted mean densities values, particularly for some of the less frequent or rare species, should not bear any significant consequences on our conclusions. However, this caveat should be considered when interpreting our results.

We did not use hypothesis testing in our analyses because of the high variation in the data, and the large number of possible comparisons across habitats, taxa, and studies in the analytical design. Instead, throughout the paper, we describe broadly observable patterns and particularly important results qualitatively.

\section{Results}

\section{Nekton Density Data Compilation}

We identified a total of 841 publications from our literature search, of which 121 publications passed the initial screening criteria (Fig. S1 in Supplement 1). When papers contained duplicate data from the same study, we maintained the most recent document and discarded the other(s). After removing 15 papers that contained duplicate data, we compiled nekton data from 106 publications (Fig. S1 and Table S6 in Supplement 1), spanning from Florida to Texas (Fig. 1).

Of the 106 papers that we compiled, we included data from 47 publications in the meta-analysis (Fig. S1 and Table S6 in Supplement 1). The majority of studies included in the metaanalysis were located in Louisiana and Texas; marsh and open-water NVB were the habitat types most commonly included in these studies (Table 1). The studies spanned over four decades, from 1962 to 2010, with the majority of studies conducted in the 1980s, 1990s, and 2000s.

\section{Gear Efficiency Data Compilation}

We identified a total of 42 publications that reported capture or recovery efficiency values (Table S1 in Supplement 2). Gear efficiency values varied among gear types, with enclosure gears (e.g., drop net, throw trap, drop sampler) generally having higher gear efficiencies than towed gears (e.g., otter trawl, seine) (Table 2).

\section{Nekton Densities Across Habitat Types}

Total nekton and crustacean densities were higher in structured habitats (e.g., marsh, oyster reefs, SAV) than in openwater NVB habitats during both spring and fall in the saline zone (Fig. 2). Total fish density was somewhat higher in structured habitats during fall, but during spring the highest densities were in oyster reef habitat with densities in the other structured habitats (i.e., marsh, SAV) slightly lower than NVB habitat (Fig. 2). While total nekton densities were similar between spring and fall in marsh, SAV, and open-water NVB habitats, total nekton densities in oyster reef habitat were nearly three times higher during spring than fall; only a few taxa (i.e., flatback mud crab (Eurypanopeus depressus), Atlantic mud crab (Panopeus herbstii), and green porcelain crab (Petrolisthes armatus)) appeared to drive these differences, and variability among studies was high. Several fish (e.g., darter goby (Ctenogobius boleosoma), pinfish (Lagodon rhomboides, spring)) and crustacean (e.g., blue crab (C. sapidus, fall), brown shrimp (F. aztecus, fall), white shrimp (L. setiferus, fall), daggerblade grass shrimp (P. pugio, spring)) species showed a similar pattern to overall nekton density, with higher densities in structured habitats than in open-water NVB habitats (Figs. 3 and 4). In contrast, bay anchovy (Anchoa mitchilli), Gulf menhaden (B. patronus, spring), and spot (Leiostomus xanthurus, spring) showed an opposite pattern, with higher densities in open-water NVB than structured habitats (Fig. 4).

We also compared the relative abundance of fish and crustacean taxa among habitat types to assess differences in community composition. Crustacean and fish community composition, including species from the families Palaemonidae (grass shrimp), Penaeidae (penaeid shrimp), Fundulidae (killifish), Gobiidae (gobies), and Sparidae [primarily pinfish (L. rhomboides, spring), appeared to be relatively similar in marsh and SAV habitats (Figs. 5 and 6 (spring), Figs. S2-S3 in Supplement 1 (fall)). Open-water NVB and oyster reef habitats, however, appeared to have unique community compositions compared to the other habitat types (Figs. 5 and 6 (spring), Figs. S2-S3 in Supplement 1 (fall)). Species in the families Penaeidae (penaeid shrimp), Porcellanidae (porcelain crabs), Xanthidae (Xanthid crabs), Clupeidae (primarily Gulf menhaden (B. patronus, spring)), and Engraulidae (anchovies) were associated with the open-water NVB habitat. Oyster reef habitat consisted of species in the families Panopeidae (mud crabs), Batrachoididae (primarily toad fish (Opsanus tau)), Gobiidae (gobies), and Sparidae (primarily pinfish (L. rhomboides, spring)) (see Table S7 in Supplement 1 for the complete list of species densities by habitat type). 


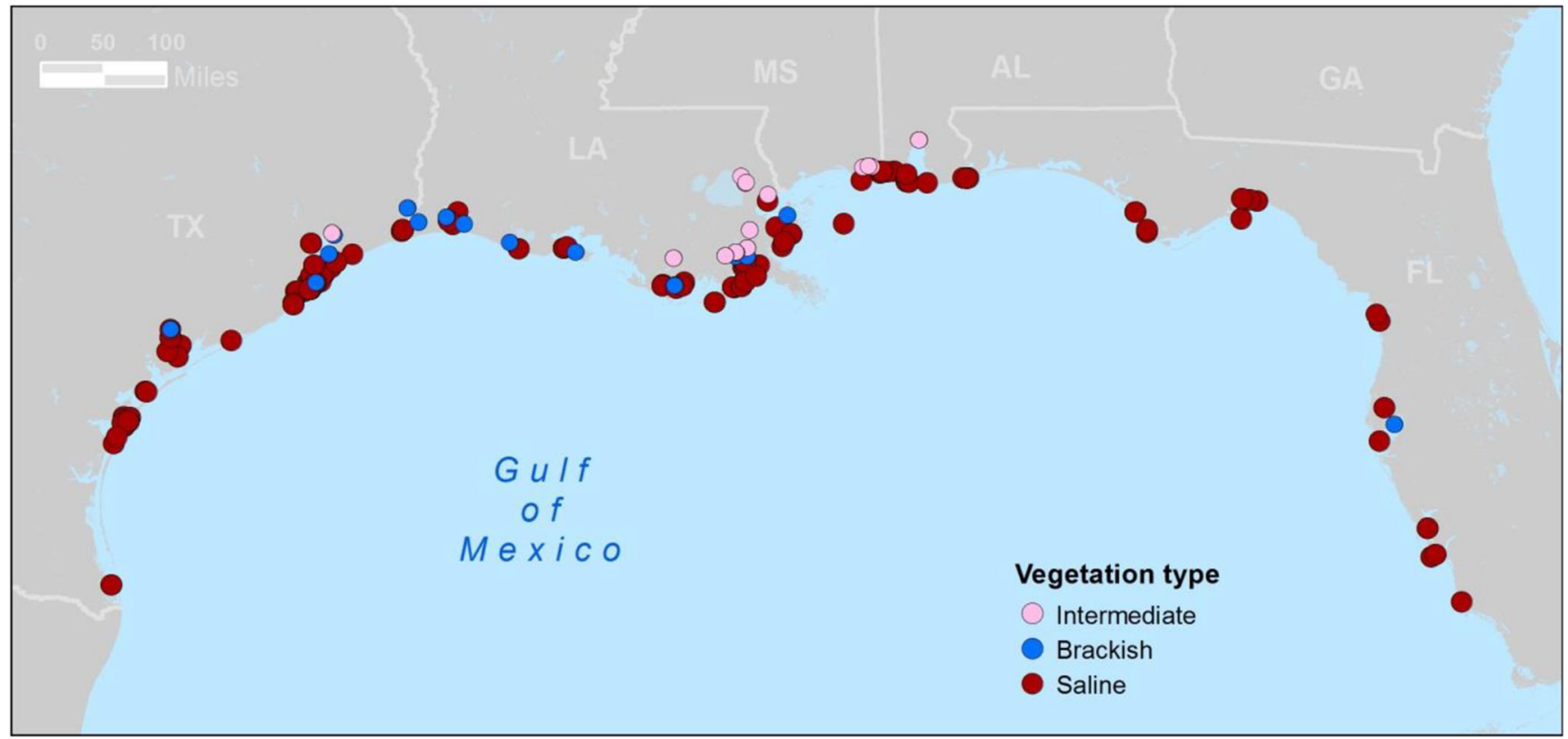

Fig. 1 Location of study sites compiled into the database by vegetation type. At a particular study site, sampling may be conducted at multiple habitat types, landscape positions (e.g., edge, interior), and seasons. Map

\section{Nekton Densities Within Marsh Habitat}

\section{Landscape}

Nekton densities were compared along the transition zone between saline marsh and open-water NVB habitats (hereafter the "marsh landscape"). Total nekton density was highest in the marsh edge habitat, followed by marsh interior habitat, and was lowest in open-water NVB habitat, with a similar pattern observed during both spring and fall (Fig. 7). This trend was driven primarily by total crustacean density, which was more than an order of magnitude higher in marsh edge habitat than open-water far habitat, and higher than both open-water near and marsh interior habitats. Total fish density was similar across the marsh landscape. excludes study sites that only reported aggregated data across multiple seasons, habitat types, or vegetation types

Densities of many crustacean species also were relatively higher on the marsh edge than in the marsh interior and openwater NVB habitats (Fig. 8). In contrast, density patterns of fish species appeared to be more variable across taxa (Fig. 9). Whereas some fish species (e.g., darter goby (C. boleosoma)) had relatively higher densities at the marsh edge compared to marsh interior or open-water NVB habitats, other species (e.g., sheepshead minnow (Cyprinodon variegatus), Gulf killifish (Fundulus grandis)) had relatively higher densities in the marsh interior than the other two habitat types. Moreover, bay anchovy (A. mitchilli) and Gulf menhaden (B. patronus) had relatively higher densities in the open-water NVB than marsh habitat, with higher densities near the marsh edge than further away (see Table S8 in Supplement 1 for the complete list of species densities by landscape position).
Table 1 Number of studies (and sampling events or records) by state, habitat type, and vegetation type included in the metaanalysis. The meta-analysis excluded studies and sampling events that reported aggregated data across multiple seasons, habitat types, or vegetation types. Since studies conducted sampling in multiple habitats, the same study may be listed in more than one habitat type or vegetation type

\begin{tabular}{llllllc}
\hline & Alabama & Florida & Louisiana & Mississippi & Texas & Total \\
\hline Marsh & $1(2)$ & $1(3)$ & $10(33)$ & $1(2)$ & $19(149)$ & $32(189)$ \\
Saline & - & $1(3)$ & $3(10)$ & $1(2)$ & $16(137)$ & $21(152)$ \\
Brackish & - & - & $2(10)$ & - & $2(10)$ & $4(20)$ \\
Intermediate & $1(2)$ & - & $5(13)$ & - & $1(2)$ & $7(17)$ \\
Open-water NVB & - & $7(35)$ & $5(10)$ & $1(2)$ & $16(155)$ & $29(202)$ \\
Saline & - & $7(35)$ & $5(10)$ & $1(2)$ & $16(155)$ & $29(202)$ \\
Oyster reefs & - & $2(3)$ & $1(4)$ & $2(20)$ & $2(4)$ & $7(31)$ \\
Saline & - & $2(3)$ & $1(4)$ & $2(20)$ & $2(4)$ & $7(31)$ \\
SAV & $1(5)$ & $3(22)$ & - & - & $10(51)$ & $14(78)$ \\
Saline & $1(5)$ & $3(22)$ & - & - & $10(51)$ & $14(78)$ \\
\hline
\end{tabular}


Table 2 Average gear efficiency (and SEs) by gear type and habitat type used in density estimation Justifications for combinations used in the analysis are given in table notes. Only gear-habitat type combinations used in this manuscript are presented

\begin{tabular}{lllll}
\hline Gear type & Marsh & Open-water NVB & Oyster reefs & SAV \\
\hline Beam trawl $^{\mathrm{a}}$ & - & $0.41(0.036)$ & - & $0.41(0.036)$ \\
Block net $_{\text {Drop net }}^{\mathrm{a}}$ & - & $0.57(0.071)$ & - & - \\
Drop sampler $_{\text {Epibenthic sled }}^{\mathrm{a}}$ & - & - & - & $0.86(0.026)$ \\
Lift net $^{\text {Otter trawl }}$ & $-0.86(0.054)$ & $0.90(0.168)$ & $0.90(0.036)$ & $0.79(0.117)$ \\
Seine $^{\mathrm{a}}$ & - & - & - & $0.74(0.069)$ \\
Substrate tray $^{\mathrm{a}}$ & - & $0.36(0.066)$ & $0.52(0.097)$ & - \\
Throw trap $_{\text {Trawl, not specified }}^{\mathrm{a}}$ & - & - & - & $0.24(0.080)$ \\
\hline
\end{tabular}

${ }^{\text {a }}$ Recovery efficiency was assumed to be $100 \%$, as these gear types do not typically have a secondary removal method

${ }^{\mathrm{b}}$ The average of beam trawl and otter trawl efficiencies across habitats

\section{Vegetation Type (Proxy for Salinity)}

Total nekton density was highest in the saline zone compared to the brackish and intermediate zones during both the spring and fall, primarily driven by total crustacean density (Fig. 10). Most

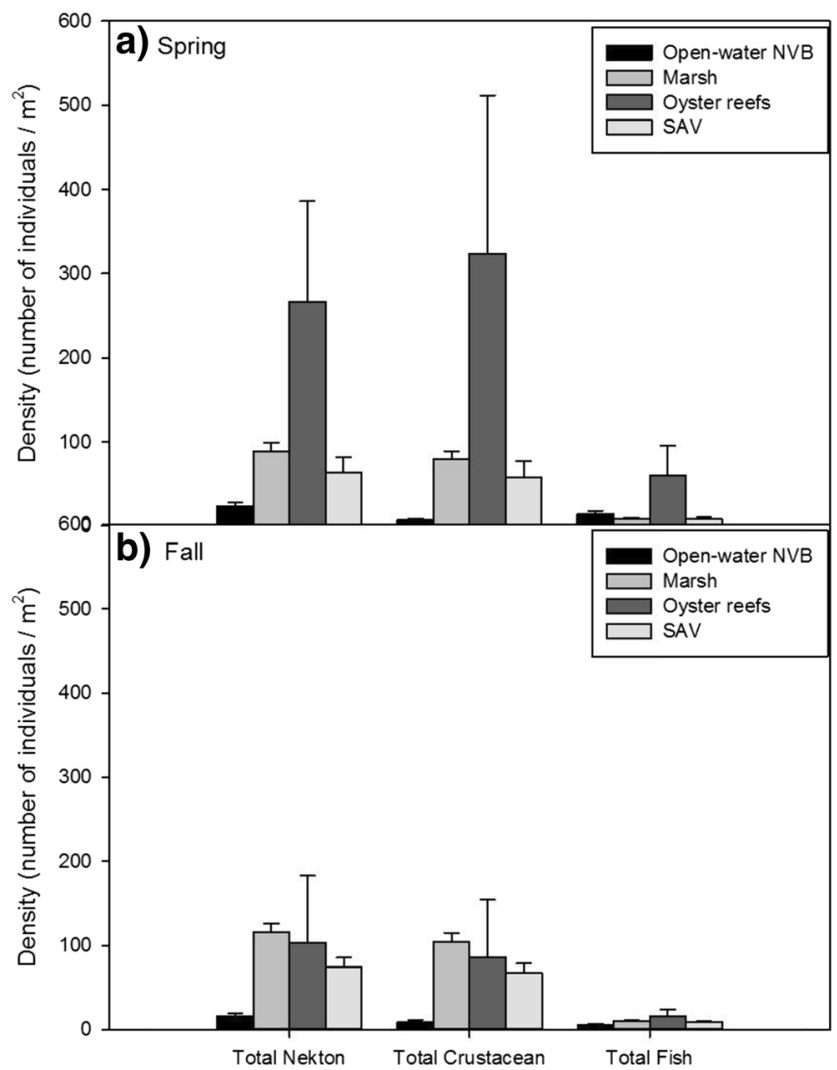

Fig. 2 Estimated means ( $\pm 1 \mathrm{SE}$ ) of total nekton density (sum of crustacean and fish species), total crustacean density, and total fish density in open-water NVB, marsh, oyster reefs, and SAV habitats during the (a) spring and (b) fall. For comparison, this analysis was limited to sampling conducted in the saline zone crustacean species analyzed were more abundant in saline marsh (e.g., blue crab (C. sapidus), brown shrimp (F. aztecus), white shrimp (L. setiferus), brackish grass shrimp ( $P$. intermedius), daggerblade grass shrimp ( $P$. pugio)). However, there were some exceptions. For example, the Harris mud crab (Rhithropanopeus harrisii) was more abundant in intermediate marsh and riverine grass shrimp (Palaemonetes paludosus) was only found in intermediate marsh (Fig. 11).

In contrast, total fish densities had an inverse relationship with salinity, with higher densities in intermediate marsh compared to saline and brackish marsh (Fig. 10). At the species level, a number of fish species had a higher density in the lower salinity vegetation types (brackish or intermediate), such as Gulf menhaden (B. patronus, spring), sheepshead minnow (C. variegatus), bayou killifish (Fundulus pulvereus), mosquitofish (Gambusia affinis), rainwater killifish (Lucania parva), and sailfin molly (Poecilia latipinna) (Fig. 12). Several commercially and recreationally important fish species, however, were most abundant in saline marshes; these included spotted seatrout (Cynoscion nebulosus, fall), spot (L. xanthurus, spring), striped mullet (Mugil cephalus, spring), southern flounder (Paralichthys lethostigma, spring), and red drum (S. ocellatus, fall) (Table S9) (see Table S9 in Supplement 1 for the complete list of species densities by vegetation type).

\section{Discussion}

Despite the clear ecological and commercial importance of shallow estuarine habitats to nekton species, few studies have summarized patterns of nekton utilization across habitat types, landscapes, and seasons at regional or global scales (e.g., Minello 1999; Minello et al. 2003; Hijuelos et al. 2017). In this study, we developed a meta-analytical approach to 
Fig. 3 Estimated mean densities ( $\pm 1 \mathrm{SE}$ ) of the 10 most abundant crustacean species of the 50 taxa analyzed by habitat type (i.e., open-water NVB, marsh, oyster reefs, and SAV) during the (a) spring and (b) fall. For comparison, this analysis was limited to sampling conducted in the saline zone
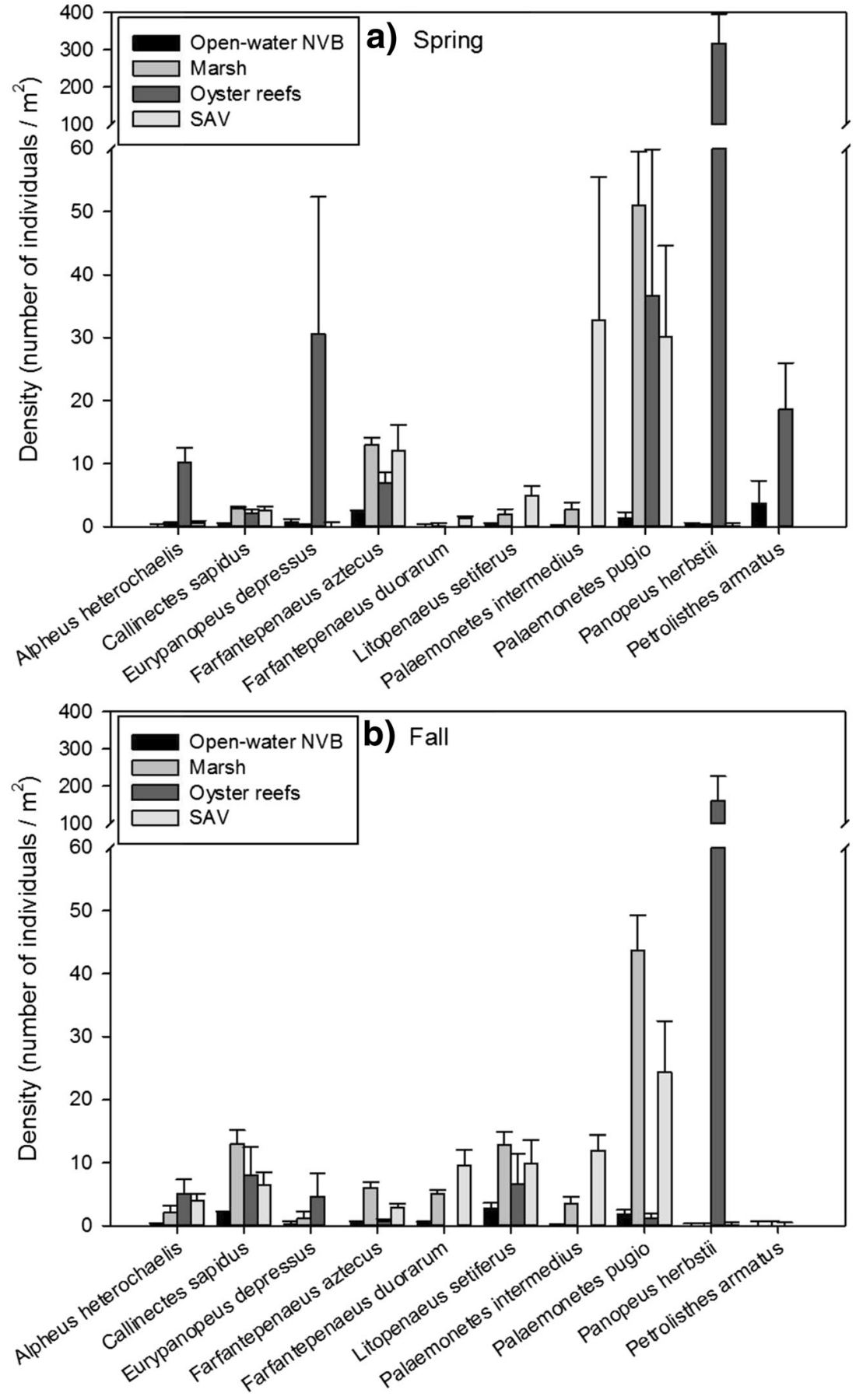

combine separate nekton density datasets (using different gear types) to evaluate patterns in nekton use across studies. After applying this meta-analytical approach to compiled nekton data collected in estuarine habitats throughout the northern GOM, we were able to identify key patterns among and within habitat types, and across salinity zones and seasons. These patterns are generally supported by site-specific studies in the region, many of which were included in our meta-analysis, and provide further evidence for these patterns at a regional scale.
Overall, we found higher nekton densities were associated with structured estuarine habitats (i.e., marsh, oyster reefs, SAV) than with open-water NVB habitat. Further, the structure of nekton communities varied among these habitat types. Marsh and SAV assemblages were similar, but different from those associated with open-water NVB and oyster habitats. In addition, densities of recreationally and commercially important crustacean and fish species were highest in saline marshes, thus demonstrating the importance of salt marsh habitats in the northern GOM. 
Fig. 4 Estimated mean densities $( \pm 1 \mathrm{SE}$ ) of the 10 most abundant fish species of the 50 taxa analyzed by habitat type (i.e., open-water NVB, marsh, oyster reefs, and SAV) during the (a) spring and (b) fall. For comparison, this analysis was limited to sampling conducted in the saline zone
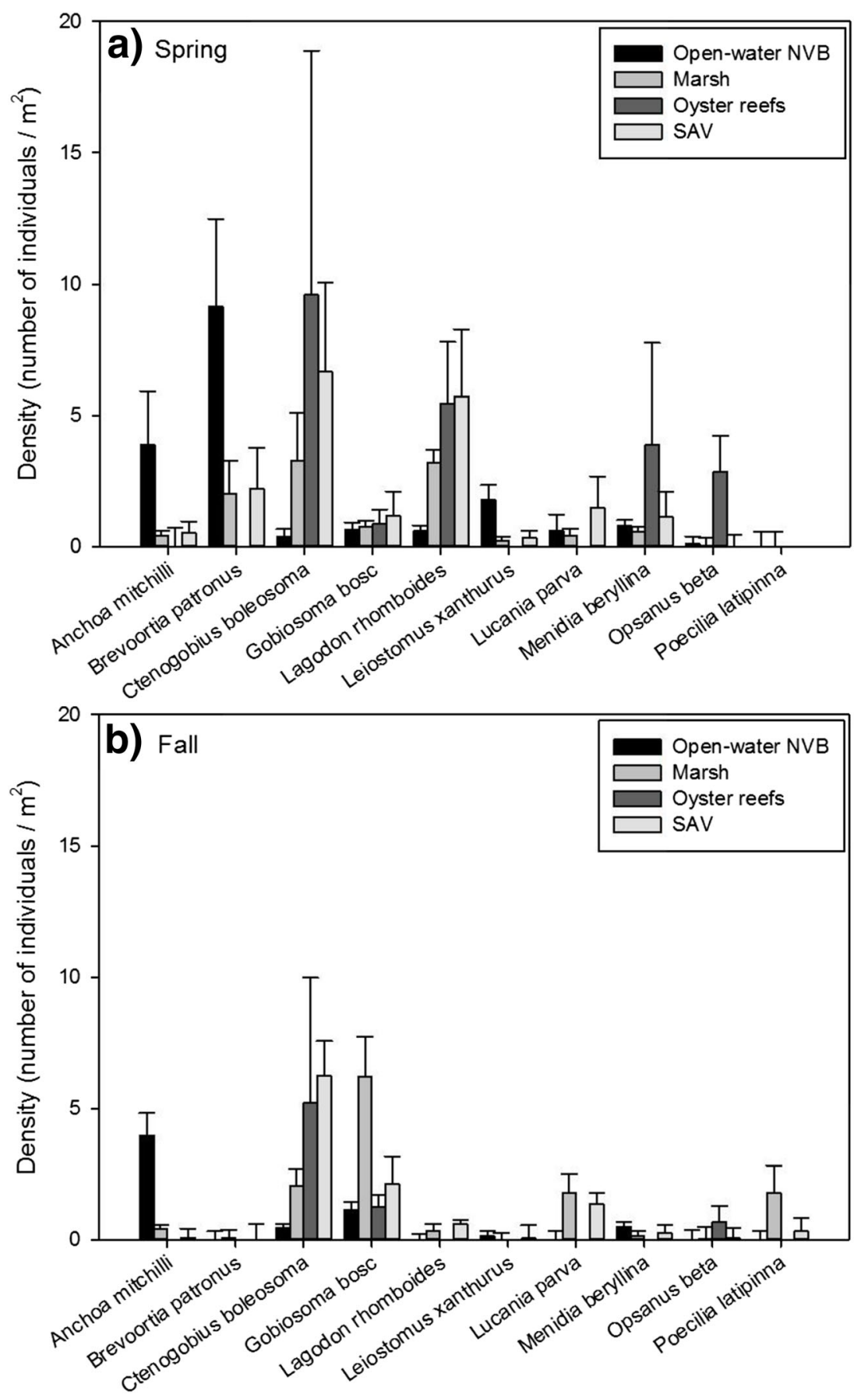

\section{Nekton Densities Across Habitat Types}

The results of our meta-analysis evaluating patterns of nekton utilization across habitat types is consistent with numerous site-specific studies, some of which were included in our meta-analysis, as well as regional and global analyses. For example, many site-specific studies in the GOM have documented higher densities of many nekton species in marsh, SAV, or oyster habitats than NVB habitat (e.g., Rozas and Minello 1998, 2006; Castellanos and Rozas 2001; Shervette and
Gelwick 2008; Stunz et al. 2010; Shervette et al. 2011). In addition, in an analysis of 22 studies conducted in shallow estuarine habitats of Texas and Florida, Minello (1999) documented higher total crustacean densities in marsh edge, SAV, and oyster reefs, with lowest densities in shallow open-water NVB. Similar to our findings, total fish densities were more comparable, with means ranging from 10.1-19.0 individuals per $\mathrm{m}^{2}$ across habitat types (Minello 1999).

Site-specific studies in the GOM (many of which were included in our meta-analysis) also support our finding that 
a) Open-water NVB

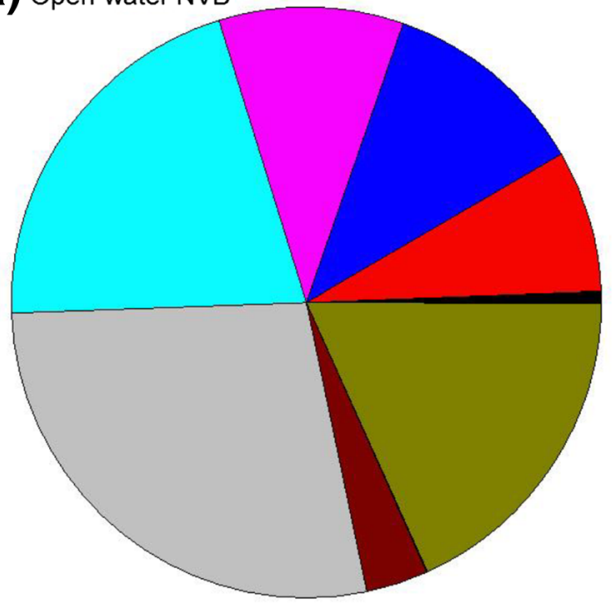

C) Oyster reefs

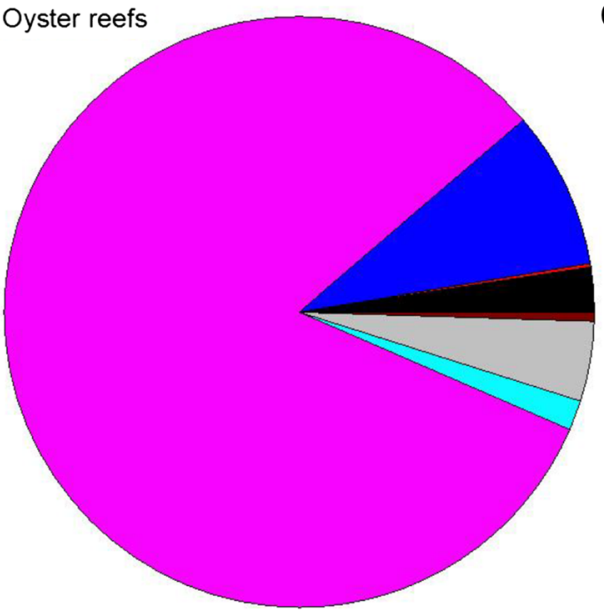

Fig. 5 Relative abundance of crustacean families in the spring by habitat type. Wedge size corresponds to the proportional densities of each family relative to the total family densities for each habitat type reported in

densities of most fish and crustacean species, as well as community composition, were relatively similar between marsh and SAV habitats (e.g., Rozas and Minello 1998; Castellanos and Rozas 2001; Rozas and Minello 2006). For example, Castellanos and Rozas (2001) found that among vegetation types in a tidal freshwater system, most species showed no apparent preference between SAV and marsh habitats. Similarly, Rozas and Minello (2006) found that in an oligohaline system marsh and SAV habitats supported similar densities for most species, with a few exceptions. Variations in nekton densities across these two vegetated habitat types were found to be related to vegetative complexity (Rozas and Minello 1998), water depth (Rozas and Minello 1998; Rozas and Minello 2006), and distance to edge (Rozas and Minello 2006). However, there are inconsistencies to this trend across individual studies, species, and seasons. For example, a study by Rozas et al. (2012) found that pink shrimp (Farfantepenaeus duorarum), daggerblade grass shrimp (P. pugio, spring), rainwater killifish (L. parva, spring), and

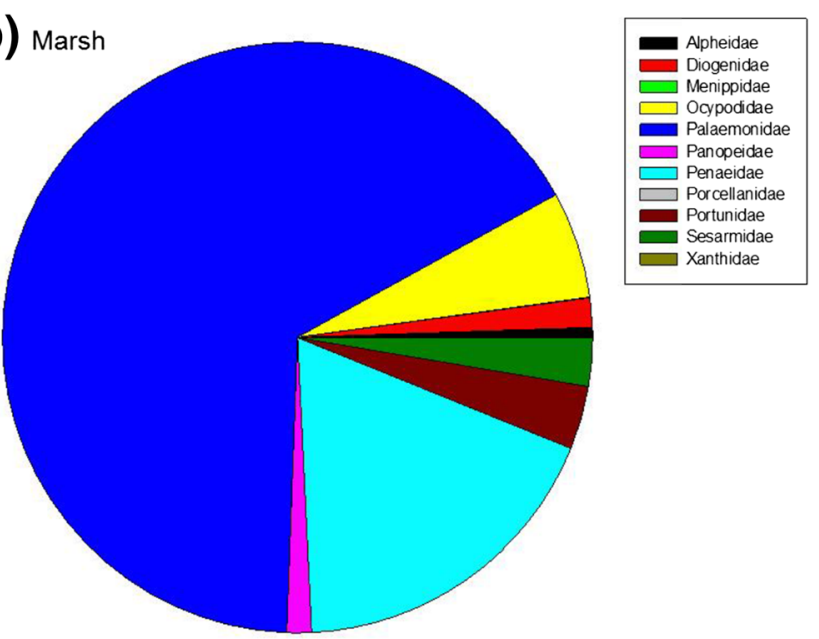

d) SAV

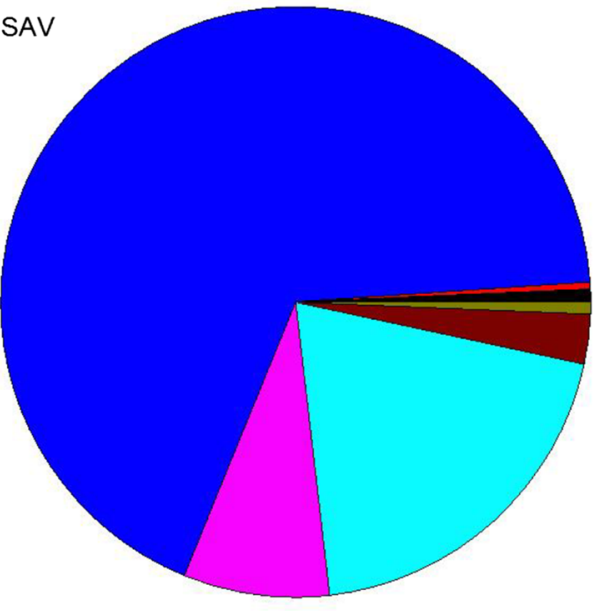

spring. Habitat types include (a) open-water NVB, (b) marsh, (c) oyster reefs, and (d) SAV during the spring. For comparison, this analysis was limited to sampling conducted in the saline zone

bigclaw snapping shrimp (A. heterochaelis, fall) were all more abundant in seagrass beds than Spartina edge. While water depth and distance to edge explained some of the variability in nekton densities within a habitat type, environmental characteristics were relatively similar across marsh and seagrass habitat types and could not explain the observed differences in nekton distribution patterns (Rozas et al. 2012). In addition, in a meta-analysis of 32 studies conducted worldwide (but primarily focused in the GOM and mid-Atlantic coast), Rozas et al. (2003) found generally higher fish and crustacean densities in seagrass compared to vegetated marsh, but this pattern was stronger along the Atlantic coast compared to the Gulf coast.

Oyster reef habitat supported higher densities of several nekton species, and different assemblages, than other habitat types. Several other site-specific studies across the GOM (many of which were included in our meta-analysis) have reported that the nekton community composition of oyster reefs differs from that of marsh (Glancy et al. 2003; 
a) Open-water NVB

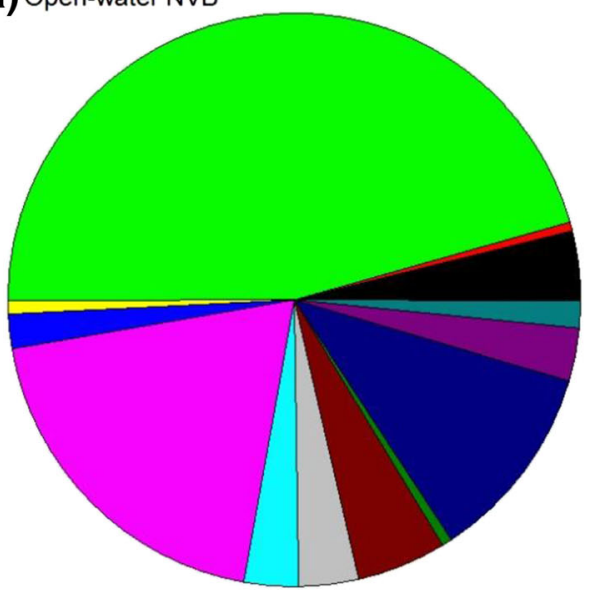

C) Oyster reefs

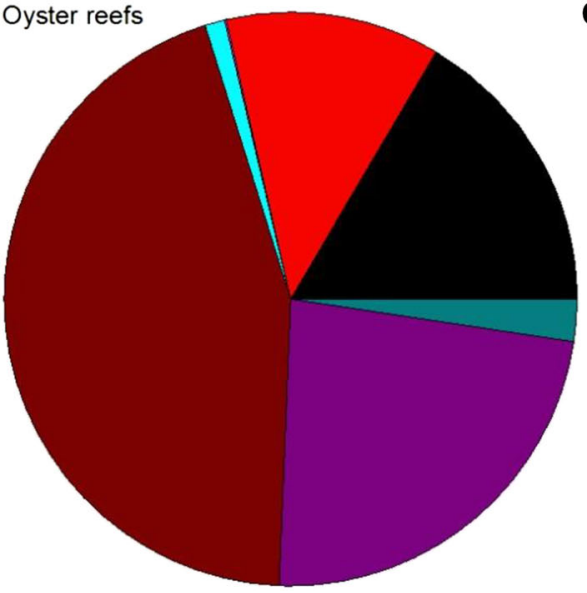

Fig. 6 Relative abundance of fish families in the spring by habitat type. Wedge size correspond to the proportional densities of each family relative to the total family densities for each habitat type reported in b) Marsh

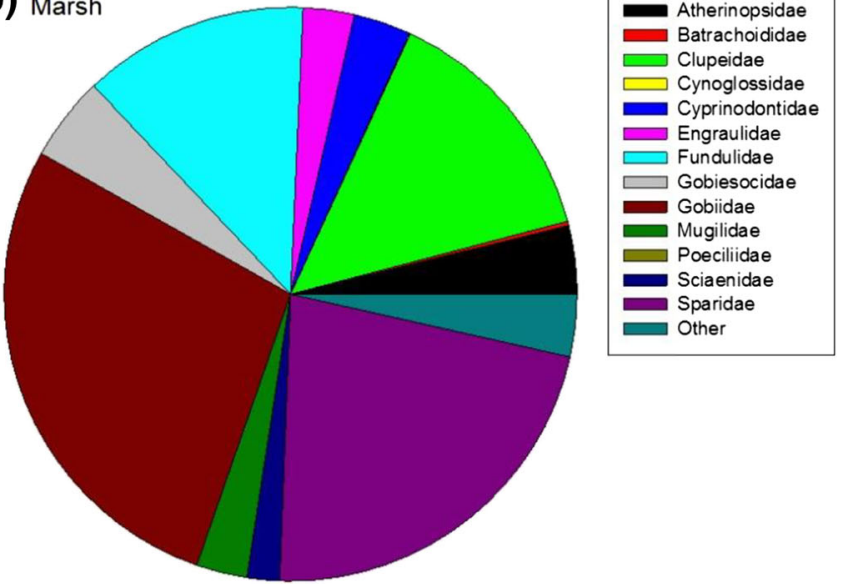

d)

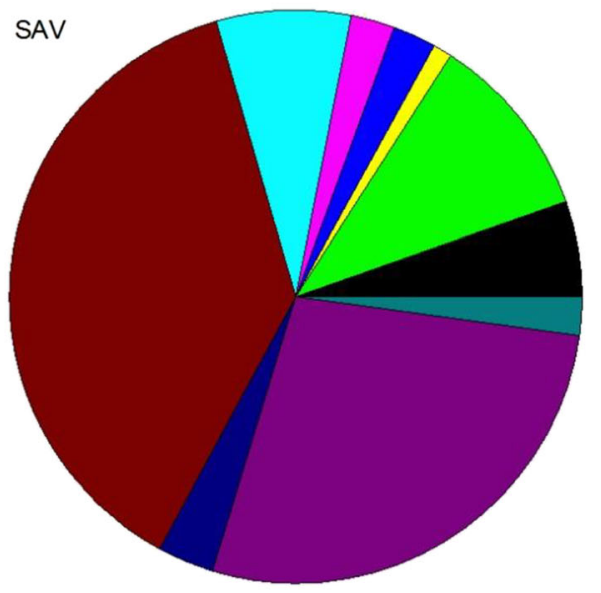

spring. Habitat types include (a) open-water NVB, (b) marsh, (c) oyster reefs, and (d) SAV during the spring. For comparison, this analysis was limited to sampling conducted in the saline zone

Shervette and Gelwick 2008; Gain 2009; Nevins et al. 2014) and SAV (Glancy et al. 2003; Gain 2009) habitats. For example, oyster reefs supported a higher density and biomass of benthic crustaceans than vegetated marsh edge, such as green porcelain crab (P. armatus), flatback mud crab (E. depressus), Atlantic mud crab (P. herbstii), mud crab (Xanthidae spp.), and snapping shrimp (Alpheidae spp.) (Stunz et al. 2010). Similarly, decapod assemblages associated with oyster reefs were distinct from those associated with seagrass and marsh edge habitats, and high densities of flatback mud crab (E. depressus), green porcelain crab (P. armatus), and Atlantic mud crab (P. herbstii) accounted for the major differences in oyster reefs compared to the other two habitat types (Glancy et al. 2003). This difference in community composition has been attributed to the unique structure of oyster reefs, which possess numerous refugia accessible to small crabs, such as mud crab (Shervette et al. 2011). Overall, our results support the idea that oyster reefs provide an ecologically unique and important habitat for fish and crustacean species (Glancy et al. 2003; Robillard et al. 2010).

\section{Nekton Densities Within Marsh Habitat}

\section{Landscape}

Across the marsh landscape, the marsh edge supports high densities of many crustacean species as well as some fish species compared to marsh interior or open-water NVB habitats. This pattern is supported by site-specific studies in Louisiana and Texas (many of which were included in our meta-analysis) that show higher nekton densities at the marsh edge compared to the marsh interior (Peterson and Turner 1994; Minello and Rozas 2002) and adjacent open-water habitat (Baltz et al. 1993; Minello et al. 2008). In Galveston Bay, Texas, densities of brown shrimp (F. aztecus), white shrimp (L. setiferus), and blue crab (C. sapidus) were highest at the marsh edge (on the marsh surface $1 \mathrm{~m}$ from the water's edge) and declined rapidly (into the vegetation) $10 \mathrm{~m}$ from the edge (Minello and Rozas 2002). A similar decline was observed for the same species based on samples collected at 1, 5, 15, 25, and $50 \mathrm{~m}$ from the marsh edge (Minello et al. 2008). Our 
Fig. 7 Estimated means ( $\pm 1 \mathrm{SE})$ of total nekton density (sum of crustacean and fish species), total crustacean density, and total fish density in open-water NVB ("near" and "far") and marsh ("edge" and "interior") during the (a) spring and (b) fall. For comparison, this analysis was limited to sampling conducted in the saline zone
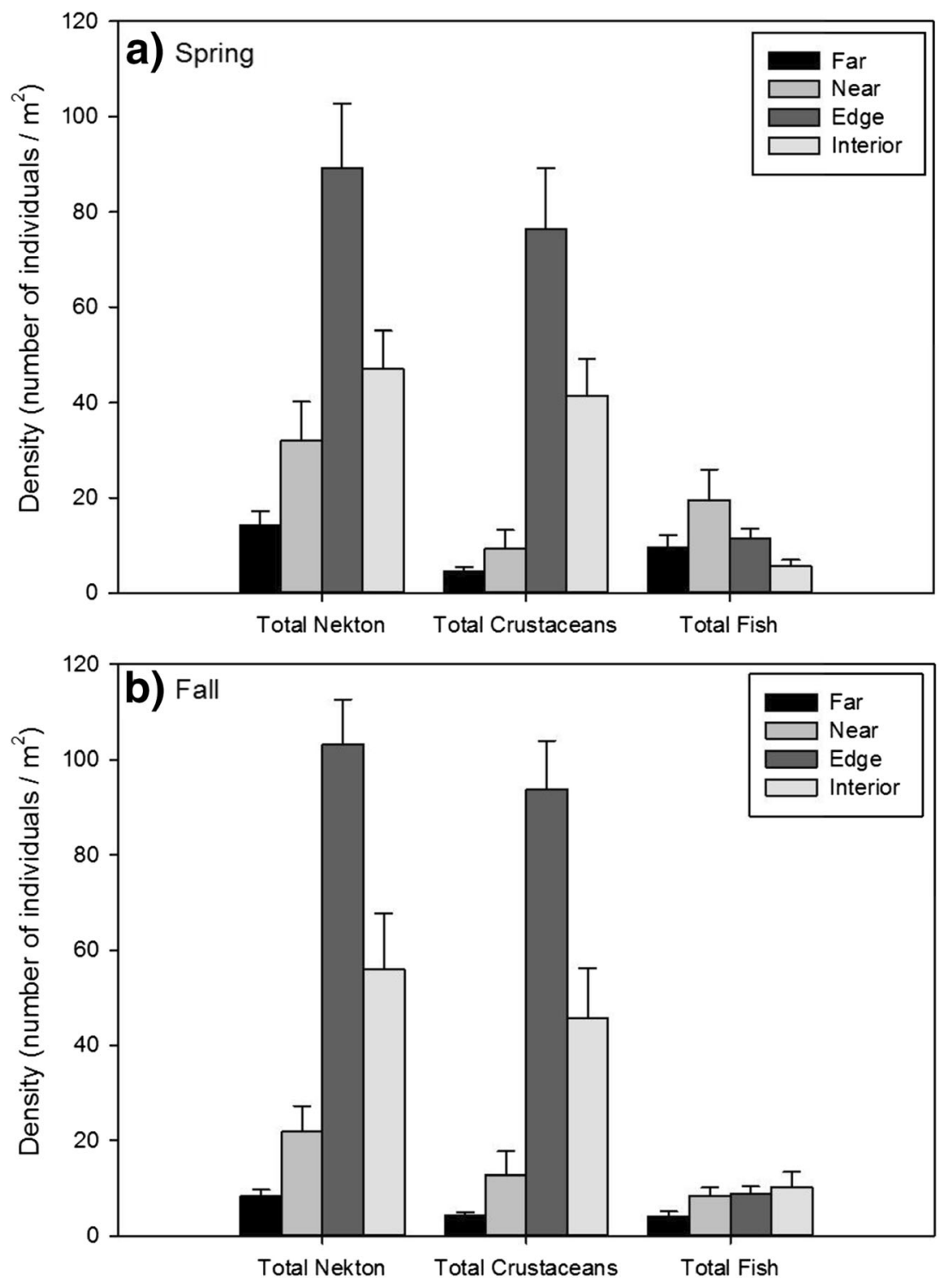

findings are also generally supported by regional and global analyses. In an analysis of 22 studies in shallow estuarine habitats of Louisiana and Texas, Minello (1999) documented higher total crustacean densities within the marsh edge compared to marsh interior and shallow open-water NVB. Total fish densities were more comparable across the landscape, but lowest in marsh interior (Minello 1999). Similarly, based on a meta-analysis of 32 studies conducted worldwide, Minello et al. (2003) found crustacean density ( 7 species) was greater in vegetated marsh edge compared to marsh interior and openwater. Fish density (29 species) was similar in vegetated marsh edge and open-water, but lower in marsh interior; however, patterns varied by individual species (Minello et al. 2003).

Many of the species that prefer the marsh edge are transient species that support GOM commercial and recreational fisheries (e.g., blue crab (C. sapidus), brown shrimp (F. aztecus), white shrimp (L. setiferus), spotted seatrout ( $C$. nebulosus), striped mullet (M. cephalus)), although some resident species (e.g., grass shrimp (Palaemonetes spp.), darter goby (C. boleosoma), Gulf killifish ( $F$. grandis), and naked goby (Gobiosoma bosc)) also appear to select the marsh edge over other habitat types (Peterson and Turner 1994). Nekton density patterns across the landscape vary by species, and are likely related to biotic and abiotic factors, such as elevation, flooding, foraging, and refuge (e.g., McIvor and Odum 1988; Rozas 1995; McIvor and Rozas 1996). Benthic infauna, important prey species for many fish and crustaceans, have been found to be most abundant at the marsh edge (Minello et al. 1994; Whaley and Minello 2002). Marsh vegetation also provides protection from predators; lower mortality rates have been measured in vegetated habitats than unstructured habitats (e.g., Minello and Zimmerman 1991; Zimmerman et al. 2000; Minello et al. 2003). 
Fig. 8 Estimated mean densities ( $\pm 1 \mathrm{SE}$ ) of the 10 most abundant crustacean species of the 50 taxa analyzed in open-water NVB ("near" and "far") and marsh ("edge" and "interior") during the (a) spring and (b) fall. For comparison, this analysis was limited to sampling conducted in the saline zone
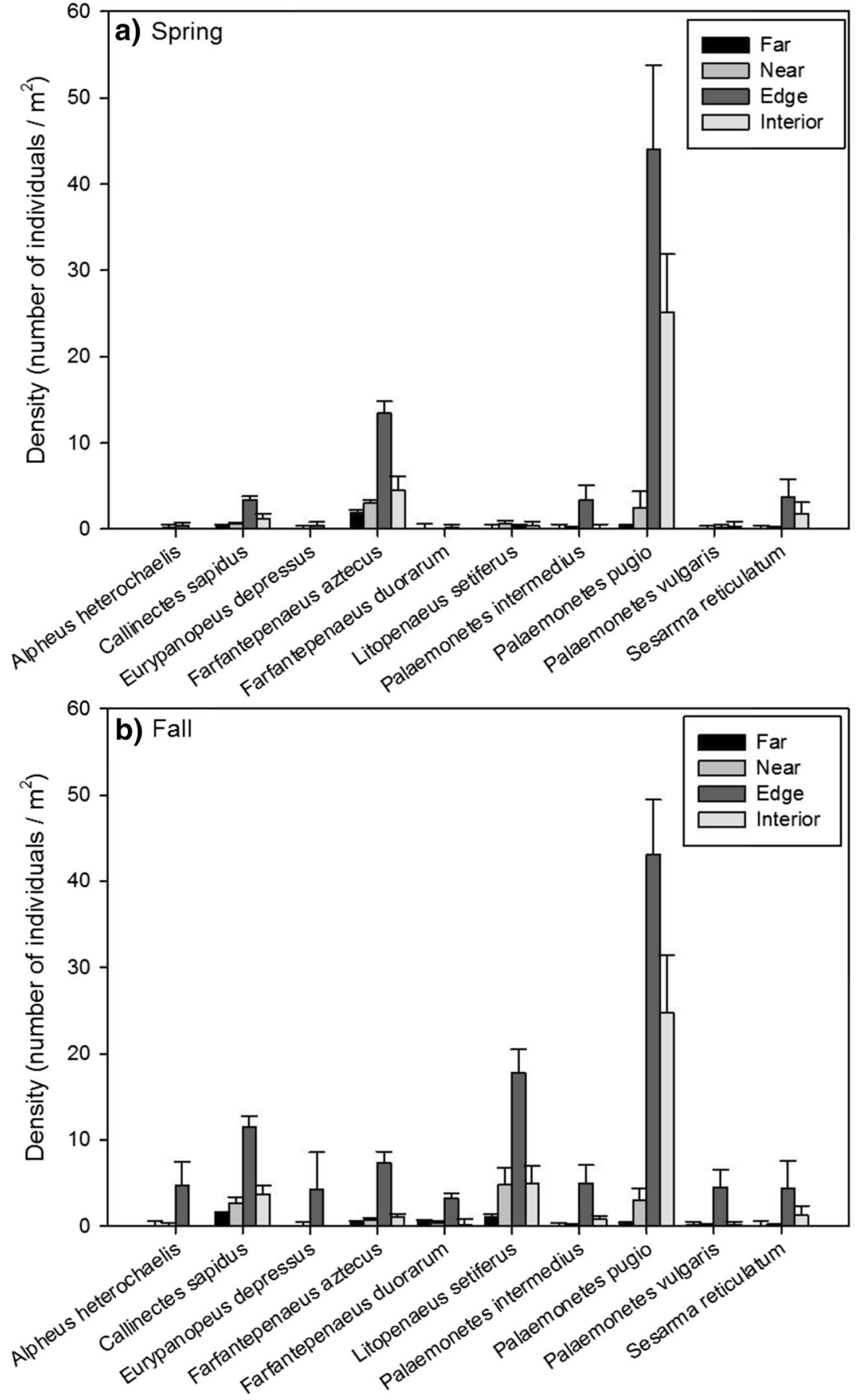

Not all species show a preference for marsh edge habitat. Some resident species are more abundant in the interior marsh (Peterson and Turner 1994; Minello and Rozas 2002). Peterson and Turner (1994) observed that interior marshes were used primarily by marsh resident species, including fiddler crab (Uca spp.), diamond killifish (Adinia xenica), sheepshead minnow ( $C$. variegatus), bayou killifish (F. pulvereus), and sailfin molly ( $P$. latipinna). These small resident species may move to interior marsh sites to seek refuge from predators (such as larger transient species) during high tide, while transient species may prefer to occupy edge habitats so they are able to quickly exit the marsh during low tide (Kneib and Wagner 1994; Peterson and Turner 1994; Kneib 1997). Resident species, such as salt marsh topminnow (F. jenkinsi), have also been found to use the interior marsh as spawning and foraging habitat (Lopez et al. 2010; Lang et al. 2012).

Recent studies have suggested, however, that the trend of higher nekton densities at the marsh edge is not necessarily conserved across marsh systems in the northern GOM (Rozas 
Fig. 9 Estimated mean densities $( \pm 1 \mathrm{SE}$ ) of the 10 most abundant fish species of the 50 taxa analyzed in open-water NVB ("near" and "far") and marsh ("edge" and "interior") during the (a) spring and (b) fall. For comparison, this analysis was limited to sampling conducted in the saline zone
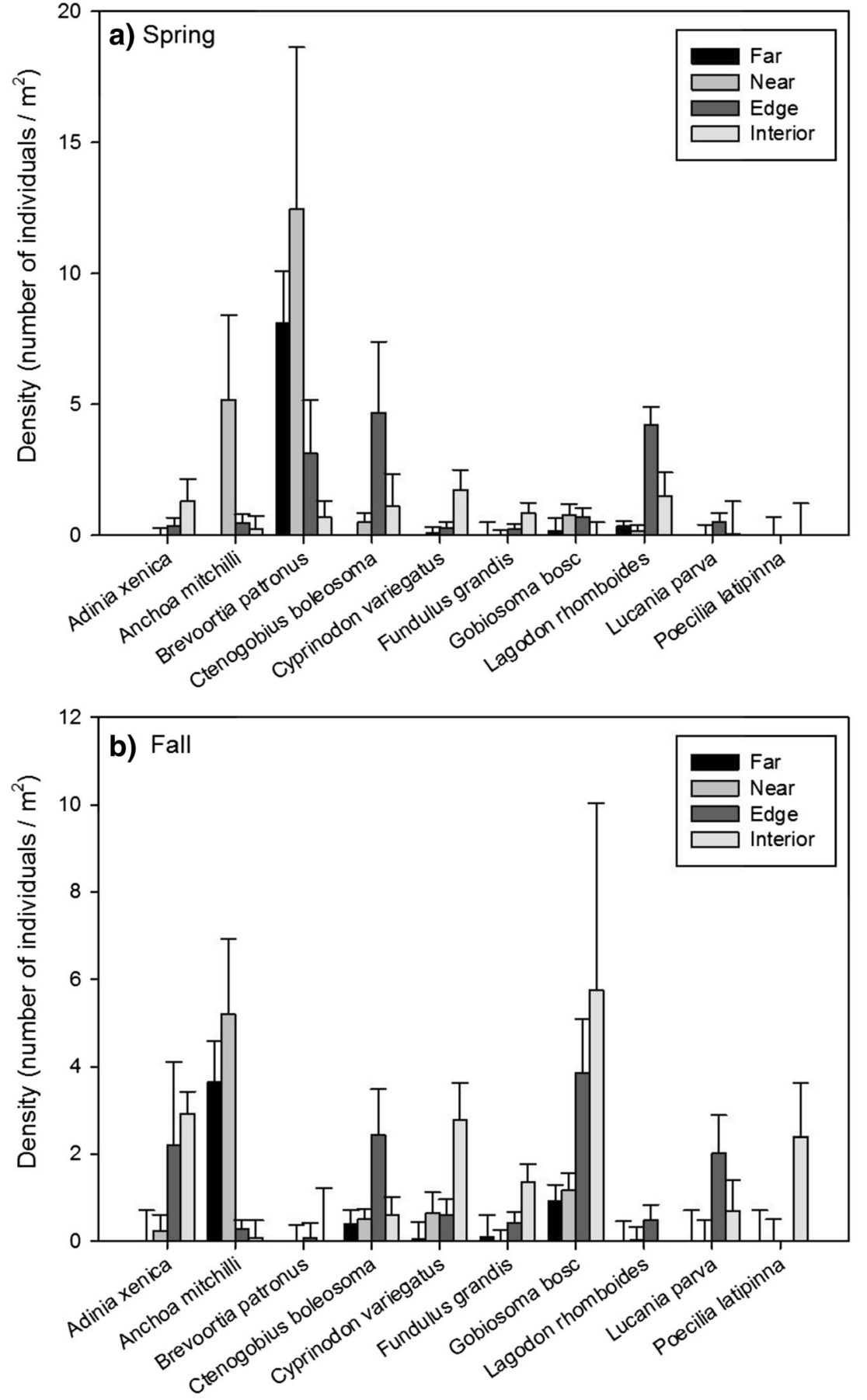

et al. 2012; Rozas and Minello 2015). Rozas and Minello (2015) found that nekton patterns in the marsh systems of Barataria Bay appeared to differ from those of Galveston Bay, with densities of white shrimp (L. setiferus), brown shrimp (F. aztecus), and blue crab (C. sapidus) not always highest at the marsh edge within the Barataria Bay system. Explanations for these potential differences include marsh elevation and slope, which influence flooding patterns of the marsh surface (Rozas and Minello 2015).

\section{Vegetation Type (Proxy for Salinity)}

Many studies have documented the effects of salinity regimes on the distribution of fish and crustaceans in estuarine systems of the GOM (e.g., Peterson and Ross 1991; Rakocinski et al. 1992; Rozas and Minello 2010; Mace and Rozas 2017) and the Atlantic Coast (e.g., Weinstein et al. 1980; Wagner and Austin 1999; Martino and Able 2003; Upchurch and Wenner 2008). Key factors that drive these patterns are physiological tolerances of the species (e.g., osmoregulation), as well as the 
Fig. 10 Estimated means ( $\pm 1 \mathrm{SE})$ of total nekton density (sum of crustacean and fish species), total crustacean density, and total fish density in saline, brackish, and intermediate marsh during the (a) spring and (b) fall

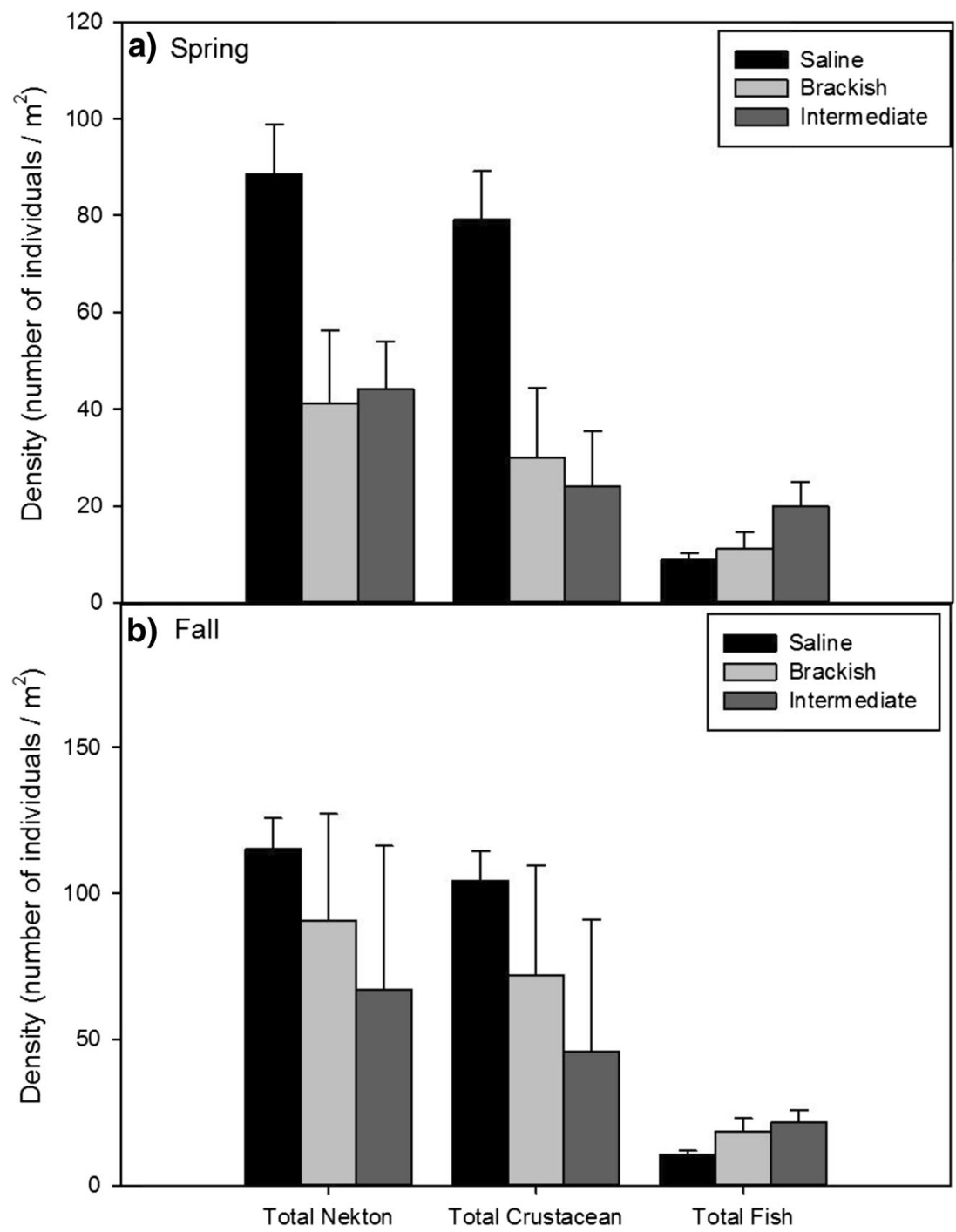

distribution of prey, predators, and competitors in the system (e.g., Werner et al. 1983; McIvor and Odum 1988; Lima and Dill 1990; Dunson and Travis 1991; Schmidt-Nielsen 1997). In addition, a relationship between salinity and size has also been observed in estuaries, with some transient species moving to higher salinity waters as they mature (e.g., Gunter 1961; Rogers et al. 1984; Able et al. 2001; Upchurch and Wenner 2008).

Our meta-analysis revealed that total nekton densities were highest in saline marshes compared to brackish to intermediate marshes. This trend was primarily driven by total crustacean density, as total fish density actually increased slightly from saline to intermediate vegetation types. Similar to the results of our meta-analysis, a site-specific study (which was included in our meta-analysis) in Barataria Bay, Louisiana, found that saline and brackish marsh supported higher total nekton densities than in intermediate zones (Rozas and Minello 2010). However, these patterns did not remain constant when moving from the marsh platform to the open-water habitat of the adjacent marsh ponds (Rozas and Minello 2010). Similarly, in Terrebonne Bay, Louisiana, higher nekton densities were reported in intermediate and freshwater marsh ponds than brackish marsh ponds within fragmented marsh, and there was no difference in nekton density among marsh types within non-fragmented marsh (Hitch et al. 2011). In addition, another study found that brackish ponds appeared to have higher or similar densities to freshwater ponds, both of which were higher than densities in saline ponds (Kang and King 2013). The authors observed differences in nekton community assemblages across habitats that were related to salinity as well as other habitat attributes, including SAV, dissolved oxygen, and hydrologic connectivity (Rozas and Minello 2010; Hitch et al. 2011; Kang and King 2013). For example, SAV cover was higher in fresh and intermediate marsh ponds compared to brackish marsh ponds, which was positively related to total nekton density (Hitch et al. 2011).

Despite the apparent differences in how total crustacean densities and total fish densities respond to salinity gradients, 
Fig. 11 Estimated mean densities ( $\pm 1 \mathrm{SE}$ ) of the 10 most abundant crustacean species of the 50 taxa analyzed in saline, brackish, and intermediate marsh during the (a) spring and (b) fall
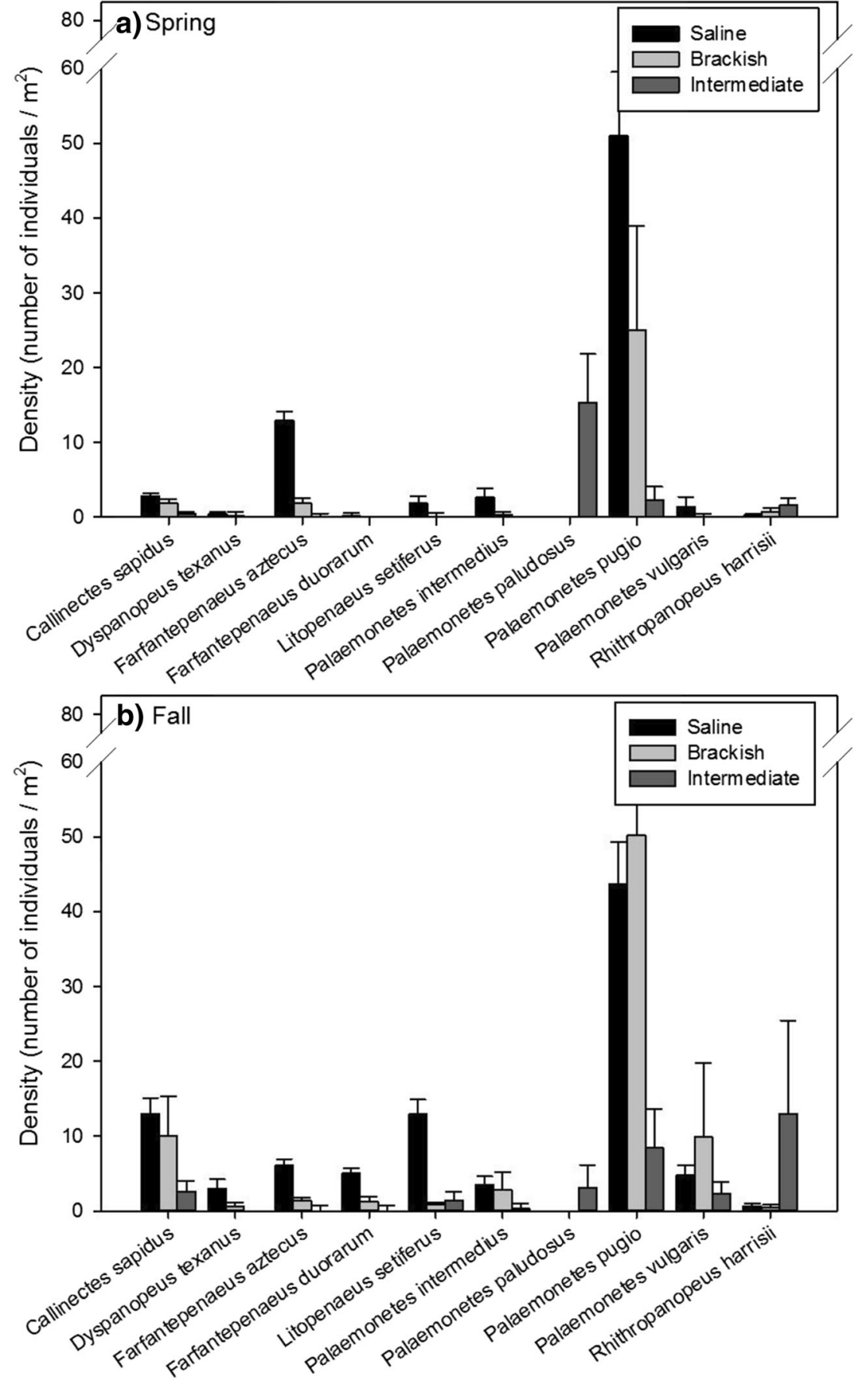

several crustaceans (e.g., blue crab (C. sapidus), brown shrimp (F. aztecus), pink shrimp (F. duorarum), white shrimp (L. setiferus)) and fish species (e.g., spotted seatrout (C. nebulosus), spot (L. xanthurus), striped mullet (M. cephalus), southern flounder (P. lethostigma), red drum (S. ocellatus)) exhibited higher relative abundances in saline marsh habitats. This observation is significant because many of these species are ecologically and economically valuable resources in the GOM. For example, blue crab (C. sapidus) and penaeid shrimp make up a significant fraction of the commercial fishery landings in the GOM (Chesney et al. 2000; O'Connell et al. 2005; NMFS 2018), and spotted seatrout ( $C$. nebulosus), striped mullet (M. cephalus), red drum ( $S$. ocellatus), and southern founder ( $P$. lethostigma) are important targets of recreational fisheries (O'Connell et al. 2005; NMFS 2018). Therefore, our observations provide further support for the notion that saline and brackish marsh habitats in the northern GOM are vital habitats for many ecologically and commercially important species (Rozas and Minello 2010). 
Fig. 12 Estimated mean densities ( $\pm 1 \mathrm{SE}$ ) of the 10 most abundant fish species of the 50 taxa analyzed in saline, brackish, and intermediate marsh during the (a) spring and (b) fall
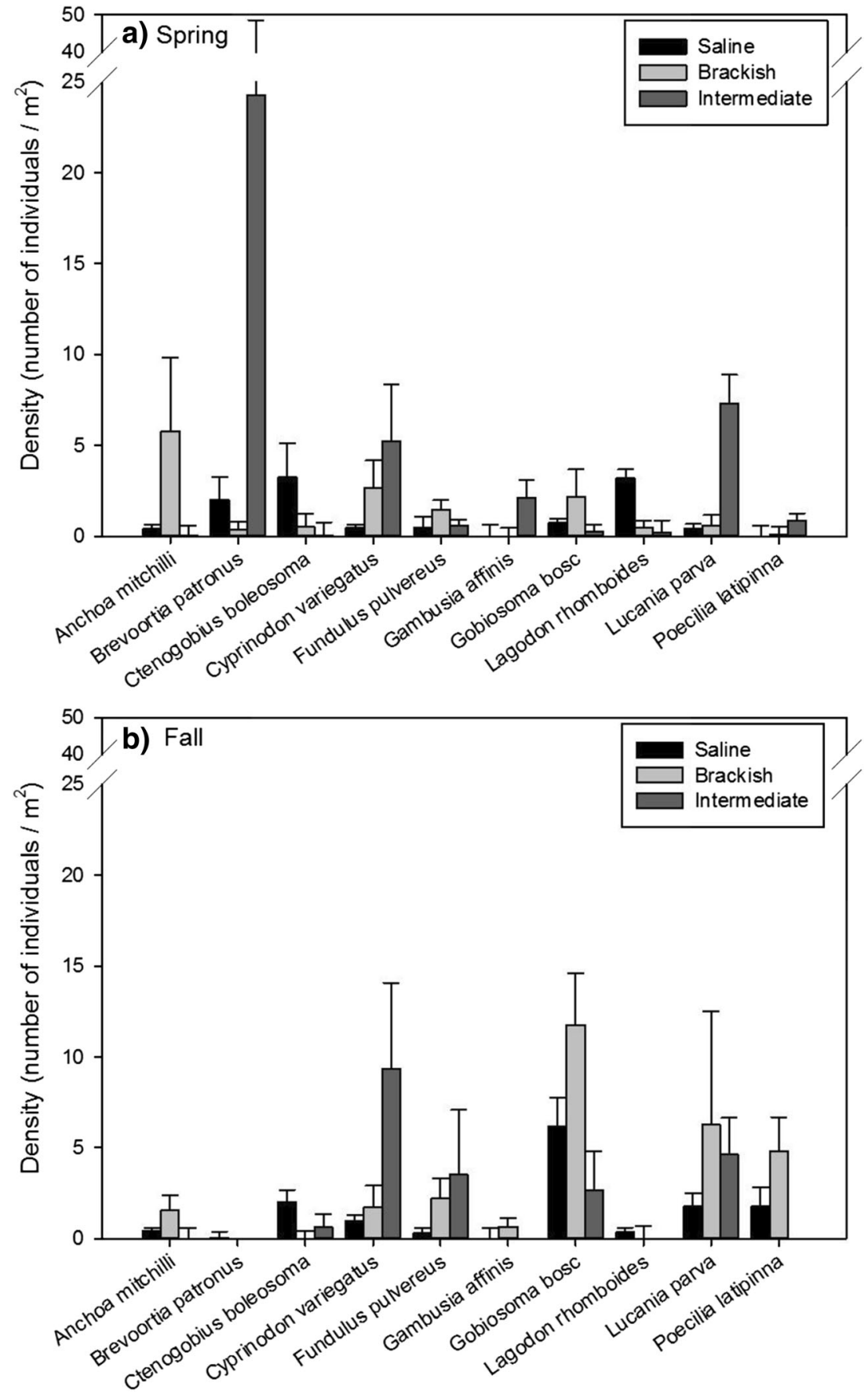

The intermediate zone, while exhibiting lower nekton densities overall, should not be dismissed for their importance to coastal fisheries. A number of fishery species use these lowsalinity zones in GOM estuaries during some portion of their life cycle (e.g., Felley 1987; Rozas and Minello 2010). For example, Gulf menhaden (B. patronus), the dominant species contributing to commercial landings in the GOM and serving an important ecological role as prey for many other species (Chesney et al. 2000; O'Connell et al. 2005; VanderKooy and Smith 2015; NMFS 2018) exhibited high densities in the intermediate zone during spring. In addition, while overall densities of some species may be lower, the large area of intermediate marsh in the northern GOM $(\sim 28 \%$ of the total marsh area from Corpus Christi Bay, Texas, to Perdido Bay, Alabama; Enwright et al. 2015) makes it a significant contributor to fisheries production in the region (Mace III and Rozas 2017). Lastly, in drought years when the estuarine isohalines shift inland, these intermediate zones may serve as important habitat to fishery species that favor more saline conditions (Mace III and Rozas 2017). 


\section{Additional Factors Affecting Nekton Patterns}

In addition to the variables we investigated in this metaanalysis (i.e., habitat type, landscape, salinity, season), other biotic and abiotic factors may affect nekton densities in coastal habitats. For example, marsh hydro-period and elevation have been observed to affect nekton use of salt marsh habitats (e.g., Rozas and Reed 1993; Kneib and Wagner 1994; Minello and Webb 1997; Rozas and Zimmerman 2000; Minello et al. 2012; Rozas and Minello 2015). Rozas and Reed (1993) found that lower elevation marshes, which were more frequently inundated, had higher densities of brown shrimp (F. aztecus) and white shrimp (L. setiferus), compared to higher-elevation marshes. This increase in inundation time would provide more access of the marsh surface to nekton, providing more time for foraging and refuge (Rozas 1995). We did not investigate the influence of marsh elevation or tidal flooding on nekton patterns; the random effect model was used to help explain some of this variability.

Nekton patterns have also been observed to vary regionally in the northern GOM, which is likely related to differences in structured environments. As discussed above, some research suggests that the trend of higher nekton densities at the marsh edge is not necessarily conserved across marsh systems in the northern GOM (Rozas et al. 2012; Rozas and Minello 2015). In addition, Rozas et al. (2012) also observed a shift in predominant habitat use by nekton to seagrass beds in the northeastern GOM, compared to the use of emergent marsh vegetation in the north-central and north-western GOM. While in our meta-analysis we observed higher densities at the marsh edge for most dominant crustacean species and did not discern strong differences in habitat use between marsh and SAV habitats, due to data limitations, we did not investigate differences in patterns among states. Since most of the study sites were located in Texas and southwestern Louisiana, it is likely that the trends we observed in our study are primary driven by nekton patterns in these states.

\section{Additional Considerations and Future Research Needs}

While the results of our meta-analysis captured broad trends in nekton utilization of coastal habitats in the northern GOM, there were some inconsistencies in patterns across taxonomic groups, seasons, and locations, and in some cases high variability when studies were aggregated. Much of this is due to the nature of working with nekton data and combining data across studies. Likely reasons for the observed variability are several fold and include

- Nekton density data are inherently highly variable due to variations in site conditions (e.g., hydro-period, elevation), habitat conditions (e.g., vegetation, soil, water quality), prey availability, other environmental conditions (e.g., temperature, salinity), disturbances (e.g., storms), and annual recruitment. While the meta-analyses aggregated data by season, salinity zone, and habitat type, there are additional site-specific factors that likely contribute to variations in nekton densities within these habitat-season combinations.

- Nekton are highly mobile, moving between coastal habitats on smaller timescales, such as hours to days and migrating across larger geographic ranges on longer timescales, such as months to years. Due to logistical and financial constraints, it is challenging to adequately sample to capture these trends.

- Low sample sizes in combination with high variability of nekton data often result in high variance and difficulty to detect differences across treatments.

- Additional sources of error related to the general analytical approach, such as aggregating data into general categories (e.g., season, salinity zone, habitat type) and standardizing data using gear correction factors. While we developed habitat-specific gear correction factors for common gear types, we acknowledge that gear efficiency may vary by user, by species, and by site conditions (e.g., water clarity, vegetative cover).

Many of these caveats are inevitable byproducts of metaanalysis that combine data from different, independent sources, such as disparate sites, times, and sampling protocols.

The results presented were also restricted to the habitatseason combinations and taxa included in the meta-analysis. For example, this study only presented corrected density data for the top 50 taxa and conducted more limited analyses in oyster reef, $\mathrm{SAV}$, and open-water NVB habitats compared to marsh habitat. In addition, many of the data included in the meta-analysis were from Louisiana and Texas. Further research looking at density patterns of specific taxa (e.g., commercially or recreationally important), other habitat-season combinations, differences in patterns across the region, and other metrics in addition density is recommended.

\section{Conclusions}

Our study provides a meta-analytical approach to aggregate densities from different studies, using different gear types, to understand key research questions. This method (1) applies gear correction factors for a variety of gear types to density estimates, (2) uses a regression approach to impute SE values for densities missing SEs, and (3) uses a random effects model to calculate weighted average densities for different treatments. Our method propagates the uncertainty of the various steps and calculations involved, thereby producing density estimates that can facilitate comparisons across habitat types, salinity zones, and seasons. This protocol is easy to implement 
for diverse research and management purposes, and can be used to advance our understanding of the value and role of coastal habitats to nekton communities.

Our meta-analysis highlighted several important trends in nekton densities associated with both relatively static (e.g., habitat type, marsh landscape) and more dynamic (e.g., season, salinity) features across estuarine habitats in the northern GOM. Overall, we found that habitat type and salinity were important drivers of variation in nekton density; in particular, structured, saline estuarine habitats tend to support relatively high densities of ecologically and commercially important crustacean and fish species. These results are consistent with many site-specific studies from the Gulf of Mexico as well as more regional and global analyses (e.g., Minello 1999; Minello et al. 2003), and provide further evidence for these patterns in nekton utilization of coastal habitats at a regional scale.

Acknowledgments The scientific results and conclusion of this publication, as well as any views or opinions expressed herein, do not necessarily represent the view of the other natural resource Trustees for the $\mathrm{BP} /$ Deepwater Horizon NRDA. The authors would like to thank Allison Ebbets, Anthony Berenguel, Ronald Hall, Timothy Meernik, Michael Carney, Sue Visser, and Matthew Rissing for their help in gathering, compiling, and quality checking data for the analysis, and Drs. Joshua Lipton, Diana Lane, and Hui Liu for providing technical insights and support. We also benefited greatly from the helpful comments of Dr. Lawrence Rozas of the NOAA Southeast Fisheries Science Center, Dr. Mark Monaco of the NOAA National Centers for Coastal Ocean Science, Dr. Tony Marshak of ECS Federal, LLC in support of the NOAA Fisheries Office of Science and Technology, and five anonymous reviewers. We also thank Diane Callow and Erin Miles for their excellent editorial support.

Funding Information This research was funded by a contract from the National Oceanic and Atmospheric Administration (NOAA) to Abt Associates (and predecessor company, Stratus Consulting) for work associated with the Deepwater Horizon oil spill.

Open Access This article is distributed under the terms of the Creative Commons Attribution 4.0 International License (http:// creativecommons.org/licenses/by/4.0/), which permits unrestricted use, distribution, and reproduction in any medium, provided you give appropriate credit to the original author(s) and the source, provide a link to the Creative Commons license, and indicate if changes were made.

\section{References}

Able, K.W. 2005. A re-examination of fish estuarine dependence: evidence for connectivity between estuarine and ocean habitats. Estuarine, Coastal and Shelf Science 64 (1): 5-17.

Able, K.W., and M.P. Fahay. 1998. The first year in the life of estuarine fishes in the Middle Atlantic Bight. New Brunswick: Rutgers University Press.

Able, K.W., D.M. Nemerson, R. Bush, and P. Light. 2001. Spatial variation in Delaware Bay (USA) marsh creek fish assemblages. Estuaries and Coasts 24 (3): 441-452.

Aitkin, M. 1999. Meta-analysis by random effect modelling in generalized linear models. Statistics in Medicine 18 (17-18): 2343-2351.
Baker, R., and T.J. Minello. 2011. Trade-offs between gear selectivity and logistics when sampling nekton from shallow open water habitats: a gear comparison study. Gulf and Caribbean Research 23 (1): 37-48.

Baltz, D.M., C. Rakocinski, and J.W. Fleeger. 1993. Microhabitat use by marsh-edge fishes in a Louisiana estuary. Environmental Biology of Fishes 36 (2): 109-126.

Beck, M.W., K.L. Heck Jr., K.W. Able, D.L. Childers, D.B. Eggleston, B.M. Gillanders, B. Halpern, C.G. Hays, K. Hoshino, T.J. Minello, R.J. Orth, P.F. Sheridan, and M.P. Weinstein. 2001. The identification, conservation, and management of estuarine and marine nurseries for fish and invertebrates. Bioscience 51 (8): 633-641.

Boesch, D.F., and R.E. Turner. 1984. Dependence of fishery species on salt marshes: the role of food and refuge. Estuaries 7 (4A): 460-468.

Casella, G., and R.L. Berger. 2002. Statistical inference. 2nd ed. Pacific Grove, California: Duxbury.

Castellanos, D.L., and L.P. Rozas. 2001. Nekton use of submerged aquatic vegetation, marsh, and shallow unvegetated bottom in the Atchafalaya River Delta, a Louisiana tidal freshwater ecosystem. Estuaries 24 (2): 184-197.

Chabreck, R.H. 1970. Marsh zones and vegetative types in the Louisiana coastal marshes. PhD Dissertation, Louisiana State University.

Chambers, J.R. 1992. Coastal degradation and fish population losses. In Stemming the tide of coastal fish habitat loss, ed. R.H. Stroud, 45 51. Savannah: National Coalition for Marine Conservation.

Chesney, E.J., D.M. Baltz, and R.G. Thomas. 2000. Louisiana estuarine and coastal fisheries and habitats: perspectives from a fish's eye view. Ecological Applications 10 (2): 350-366.

Deegan, L.A. 1993. Nutrient and energy transport between estuaries and coastal marine ecosystems by fish migration. Canadian Journal of Fisheries and Aquatic Sciences 50 (1): 74-79.

Deegan, L.A., J.E. Hughes, and R.A. Rountree. 2000. Salt marsh ecosystem support of marine transient species. In In Concepts and controversies in tidal marsh ecology, 333-365. Boston, Massachusetts: Kluwer Academic Publishers.

Dunson, W.A., and J. Travis. 1991. The role of abiotic factors in community organization. The American Naturalist 138 (5): 1067-1091.

Enwright, N.M., S.B. Hartley, M.G. Brasher, J.M. Visser, M.K. Mitchell, B.M. Ballard, M.W. Parr, B.R. Couvillion, and B.C. Wilson. 2014. Delineation of marsh types of the Texas Coast from Corpus Christi Bay to the Sabine River in 2010. U.S. Geological Survey Scientific Investigations Report 2014-5110.

Enwright, N.M., S.B. Hartley, B.R. Couvillion, M.G. Brasher, J.M. Visser, M.K. Mitchell, B.M. Ballard, M.W. Parr, and B.C. Wilson. 2015. Delineation of marsh types from Corpus Christi Bay, Texas, to Perdido Bay, Alabama, in 2010. U.S. Geological Survey Scientific Investigations Map 3336, 1 sheet, scale 1:750,000. 10.3133/ sim3336. Accessed 20 September 2017.

Felley, J.D. 1987. Nekton assemblages of three tributaries to the Calcasieu estuary, Louisiana. Estuaries 10 (4): 321-329.

Gain, I. 2009. Oyster reefs as nekton habitat in estuarine ecosystems. MS Thesis, Texas A\&M University.

Glancy, T.P., T.K. Frazer, C.E. Cichra, and W.J. Lingberg. 2003. Comparative patterns of occupancy by decapod crustaceans in seagrass, oyster, and marsh-edge habitats in a northeast Gulf of Mexico estuary. Estuaries 26 (5): 1291-1301.

Goodman, L.A. 1960. On the exact variance of products. Journal of the American Statistical Association 55 (292): 708-713.

Gunter, G. 1961. Some relations of estuarine organisms to salinity. Limnology and Oceanography 6 (2): 182-190.

Higgins, J.P.T., and S. Green, editors. 2011. Cochrane handbook for systematic reviews of interventions. Version 5.1.0. The Cochrane Collaboration. http://www.cochrane-handbook.org. Accessed 1 July 2019.

Hijuelos, A.C., S.E. Sable, A.M. O'Connell, J.P. Geaghan, D.C. Lindquist, and E.D. White. 2017. Application of species distribution 
models to identify estuarine hot spots for juvenile nekton. Estuaries and Coasts 40 (4): 1183-1194.

Hilbe, J.M. 2014. Modeling count data. New York: Cambridge University Press.

Hitch, A.T., K.M. Purcell, S.B. Martin, P.L. Klerks, and P.L. Leberg. 2011. Interactions of salinity, marsh fragmentation and submerged aquatic vegetation on resident nekton assemblages of coastal marsh ponds. Estuaries and Coasts 34 (3): 653-662.

Hollweg, T.A., M.C. Christman, J. Lipton, B.P. Wallace, M.T. Huisenga, D. Lane, and K.G. Benson. 2019. Meta-analysis of nekton recovery following marsh restoration in the northern Gulf of Mexico. Submitted to same special section of Estuaries and Coasts. https:// doi.org/10.1007/s12237-019-00630-1.

Kang, S.-R., and S.L. King. 2013. Effects of hydrologic connectivity and environmental variables on nekton assemblage in a coastal marsh system. Wetlands 33 (2): 321-334.

Kneib, R.T. 1997. The role of tidal marshes in the ecology of estuarine nekton. In Oceanography and marine biology: an annual review, ed. A.D. Ansell, R.N. Gibson, and M. Barnes, 163-220. Bristol, Pennsylvania: UCL Press.

Kneib, R.T., and S.L. Wagner. 1994. Nekton use of vegetated marsh habitats at different stages of tidal inundation. Marine Ecology Progress Series 106: 227-238.

Lang, E.T., N.J. Brown-Peterson, M.S. Peterson, and W.T. Slack. 2012. Seasonal and tidally driven reproductive patterns in the saltmarsh topminnow, Fundulus jenkinsi. Copeia 2012 (3): 451-459.

Lellis-Dibble, K.A., K.E. McGlynn, and T.E. Bigford. 2008. Estuarine fish and shellfish species in U.S. commercial and recreational fisheries: economic value as an incentive to protect and restore estuarine habitat. NOAA Technical Memorandum NMFS-F/SPO-90. U.S. Department of Commerce.

Lima, S.L., and L.M. Dill. 1990. Behavioral decisions made under the risk of predation: a review and prospectus. Canadian Journal of Zoology 68 (4): 619-640.

Lopez, J.D., M.S. Peterson, E.T. Lang, and A.M. Charbonnet. 2010. Linking habitat and life history for conservation of the rare saltmarsh topminnow Fundulus jenkinsi: morphometrics, reproduction, and trophic ecology. Endangered Species Research 12 (2): 141-155.

Mace, M.M., III, and L.P. Rozas. 2017. Population dynamics and secondary production of juvenile white shrimp (Litopenaeus setiferus) along an estuarine salinity gradient. Fishery Bulletin 115 (1).

Martino, E.J., and K.W. Able. 2003. Fish assemblages across the marine to low salinity transition zone of a temperate estuary. Estuarine, Coastal and Shelf Science 56 (5): 969-987.

McIvor, C.C., and W.E. Odum. 1988. Food, predation risk, and microhabitat selection in a marsh fish assemblage. Ecology 69 (5): 1341 1351.

McIvor, C.C., and L.P. Rozas. 1996. Direct nekton use of intertidal saltmarsh habitat and linkage with adjacent habitats: a review from the southeastern United States. In Estuarine shores: evolution, environments and human alterations, ed. K.F. Nordstrom and C.T. Roman, 311-334. New York: John Wiley \& Sons.

Minello, T.J. 1999. Nekton densities in shallow estuarine habitats of Texas and Louisiana and the identification of essential fish habitat. American Fisheries Society Symposium 22: 43-75.

Minello, T.J., and L.P. Rozas. 2002. Nekton in Gulf Coast wetlands: finescale distributions, landscape patterns, and restoration implications. Ecological Applications 12 (2): 441-455.

Minello, T.J., and J.W. Webb. 1997. Use of natural and created Spartina alterniflora salt marshes by fishery species and other aquatic fauna in Galveston Bay, Texas, USA. Marine Ecology Progress Series 151: 165-179.

Minello, T.J., and R.J. Zimmerman. 1991. The role of estuarine habitats in regulating growth and survival of juvenile penaeid shrimp. In Frontiers in shrimp research, ed. P. DeLoach, W.J. Dougherty, and M.A. Davidson, 1-16. Amsterdam: Elsevier Scientific Publications.
Minello, T.J., and R.J. Zimmerman. 1992. Utilization of natural and transplanted Texas salt marshes by fish and decapod crustaceans. Marine Ecology Progress Series 90: 273-285.

Minello, T.J., L.P. Rozas, and R. Baker. 2012. Geographic variability in salt marsh flooding patterns may affect nursery value for fishery species. Estuaries and Coasts 35 (2): 501-514.

Minello, T.J., R.J. Zimmerman, and R. Medina. 1994. The importance of edge for natant macrofauna in a created salt marsh. Wetlands 14 (3): 184-198

Minello, T.J., K.W. Able, M.P. Weinstein, and C.G. Hays. 2003. Salt marshes as nurseries for nekton: testing hypotheses on density, growth and survival through meta-analysis. Marine Ecology Progress Series 246: 39-59.

Minello, T.J., G.A. Matthews, P.A. Caldwell, and L.P. Rozas. 2008. Population and production estimates for decapod crustaceans in wetlands of Galveston Bay, Texas. Transactions of the American Fisheries Society 137 (1): 129-146.

Nevins, J.A., J.B. Pollack, and G.W. Stunz. 2014. Characterizing nekton use of the largest unfished oyster reef in the United States compared with adjacent estuarine habitats. Journal of Shellfish Research 33 (1): 227-238.

NMFS. 2018. Fisheries of the United States, 2017. Current Fishery Statistics No. 2017. U.S. Department of Commerce, National Oceanic and Atmospheric Administration, National Marine Fisheries Service. Silver Spring, Maryland. September. https:// www.fisheries.noaa.gov/resource/document/fisheries-united-states2017-report. Accessed 1 July 2019.

O'Connell, M.T., C.D. Franze, E.A. Spalding, and M.A. Poirrier. 2005. Biological resources of the Louisiana coast: part 2. Coastal animals and habitat associations. Journal of Coastal Research SI 44: 146161.

Peterson, G.W., and R.E. Turner. 1994. The value of salt marsh edge vs interior as a habitat for fish and decapod crustaceans in a Louisiana tidal marsh. Estuaries 17 (1B): 235-262.

Peterson, M.S., and S.T. Ross. 1991. Dynamics of littoral fishes and decapods along a coastal river-estuarine gradient. Estuarine, Coastal and Shelf Science 33 (5): 467-483.

Quinn, G.P., and M.J. Keough. 2002. Experimental design and data analysis for biologists. Cambridge: Cambridge University Press.

Rakocinski, C.F., D.M. Baltz, and J.W. Fleeger. 1992. Correspondence between environmental gradients and the community structure of marsh-edge fishes in a Louisiana estuary. Marine Ecology Progress Series 80: 135-148.

Robillard, M.M.R., G.W. Stunz, and J. Simons. 2010. Relative value of deep subtidal oyster reefs to other estuarine habitat types using a novel sampling method. Journal of Shellfish Research 29 (2): 291 302.

Rogers, S.G., T.E. Targett, and S.B. Van Sant. 1984. Fish-nursery use in Georgia salt-marsh estuaries: the influence of springtime freshwater conditions. Transactions of the American Fisheries Society 113 (5): 595-606.

Rozas, L.P. 1995. Hydroperiod and its influence on nekton use of the salt marsh: a pulsing ecosystem. Estuaries 18 (4): 579-590.

Rozas, L.P., and T.J. Minello. 1997. Estimating densities of small fishes and decapod crustaceans in shallow estuarine habitats: a review of sampling design with focus on gear selection. Estuaries 20 (1): 199213.

Rozas, L.P., and T.J. Minello. 1998. Nekton use of salt marsh, seagrass, and nonvegetated habitats in a South Texas (USA) estuary. Bulletin of Marine Science 63 (3): 481-501.

Rozas, L.P., and T.J. Minello. 2001. Marsh terracing as a wetland restoration tool for creating fishery habitat. Wetlands 21 (3): 327-341.

Rozas, L.P., and T.J. Minello. 2006. Nekton use of Vallisneria americana Michx. (wild celery) beds and adjacent habitats in coastal Louisiana. Estuaries and Coasts 29 (2): 297-310. 
Rozas, L.P., and T.J. Minello. 2010. Nekton density patterns in tidal ponds and adjacent wetlands related to pond size and salinity. Estuaries and Coasts 33 (3): 652-667.

Rozas, L.P., and T.J. Minello. 2015. Small-scale nekton density and growth patterns across a saltmarsh landscape in Barataria Bay, Louisiana. Estuaries and Coasts 38 (6): 2000-2018. https://doi. org/10.1007/s12237-015-9945-3.

Rozas, L.P., and D.J. Reed. 1993. Nekton use of marsh-surface habitats in Louisiana (USA) deltaic salt marshes undergoing submergence. Marine Ecology Progress Series 96: 147-157.

Rozas, L.P., and R.J. Zimmerman. 2000. Small-scale patterns of nekton use among marsh and adjacent shallow nonvegetated areas of the Galveston Bay Estuary, Texas (USA). Marine Ecology Progress Series 193: 217-239.

Rozas, L.P., T.J. Minello, and D.D. Dantin. 2012. Use of shallow lagoon habitats by nekton of the northeastern Gulf of Mexico. Estuaries and Coasts 35 (2): 572-586.

Sasser, C.E., J.M. Visser, E. Mouton, J. Linscombe, and S.B. Hartley. 2014. Vegetation types in coastal Louisiana in 2013. U.S. Scientific Investigations Map 3290.

Schmidt-Nielsen, K. 1997. Animal physiology: adaptation and environment. In Fifth. Cambridge: Cambridge University Press.

Shervette, V.R., and F. Gelwick. 2008. Seasonal and spatial variations in fish and macroinvertebrate communities of oyster and adjacent habitats in a Mississippi estuary. Estuaries and Coasts 31 (3): 584-596.

Shervette, V.R., F. Gelwick, and N. Hadley. 2011. Decapod utilization of adjacent oyster, vegetated marsh, and non-vegetated bottom habitats in a Gulf of Mexico estuary. Journal of Crustacean Biology 31 (4): 660-667.

Stunz, G.W., T.J. Minello, and L.P. Rozas. 2010. Relative value of oyster reef as habitat for estuarine nekton in Galveston Bay, Texas. Marine Ecology Progress Series 406: 147-159.

Tummers, B. 2006. DataThief III. http://datathief.org/. Accessed 25 August 2017.

Upchurch, S., and E. Wenner. 2008. Fish and decapod crustacean assemblages from the Ashepoo-Combahee-Edisto Basin, South Carolina (1993-1999). Journal of Coastal Research Special Issue 55: 200 213.

VanderKooy, S.J., and J.W. Smith, eds. 2015. The Gulf menhaden fishery of the Gulf of Mexico: a regional management plan. Gulf States Marine Fisheries Commission. March. http://www.gsmfc.org/
publications/GSMFC\%20Number\%20240.pdf. Accessed 20 September 2017.

Vetter, D., G. Rücker, and I. Storch, I. 2013. Meta-analysis: a need for well-defined usage in ecology and conservation biology. Ecosphere 4(6): $1-24$

Visser, J.M., C.E. Sasser, R.H. Chabreck, and R.G. Linscombe. 1998. Marsh vegetation types of the Mississippi River Deltaic Plain. Estuaries 21 (4B): 818-828.

Visser, J.M., C.E. Sasser, R.H. Chabreck, and R.G. Linscombe. 2000 Marsh vegetation types of the Chenier Plain, Louisiana, USA. Estuaries 23 (3): 318-327.

Visser, J.M., C.E. Sasser, R.H. Chabreck, and R.G. Linscombe. 2002. The impact of a severe drought on the vegetation of a subtropical estuary. Estuaries 25 (6A): 1184-1195.

Wagner, C.M., and H.M. Austin. 1999. Correspondence between environmental gradients and summer littoral fish assemblages in low salinity reaches of the Chesapeake Bay, USA. Marine Ecology Progress Series 177: 197-212.

Weinstein, M.P., S.L. Weiss, and M.F. Walters. 1980. Multiple determinants of community structure in shallow marsh habitats, Cape Fear River Estuary, North Carolina, USA. Marine Biology 58 (3): 227 243.

Werner, E.E., J.F. Gilliam, D.J. Hall, and G.G. Mittelbach. 1983. An experimental test of the effects of predation risk on habitat use in fish. Ecology 64 (6): 1540-1548.

Whaley, S.D., and T.J. Minello. 2002. The distribution of benthic infauna of a Texas salt marsh in relation to the marsh edge. Wetlands 22 (4): 753-766.

Zeug, S.C., V.R. Shervette, D.J. Hoeinghaus, and S.E.I. Davis. 2007. Nekton assemblage structure in natural and created marsh-edge habitats of the Guadalupe Estuary, Texas, USA. Estuarine, Coastal and Shelf Science 71 (3-4): 457-466.

Zimmerman, R.J., and T.J. Minello. 1984. Densities of Penaeus aztecus, Penaeus setiferus, and other natant macrofauna in a Texas salt marsh. Estuaries 7 (4A): 421-433.

Zimmerman, R.J., T.J. Minello, and L.P. Rozas. 2000. Salt marsh linkages to productivity of Penaeid shrimps and blue crabs in the northern Gulf of Mexico. In Concepts and controversies in tidal marsh ecology, ed. M.P. Weinstein and D.A. Kreeger, 293-314. Boston, Massachusetts: Kluwer Academic Publishers. 